\title{
EL ANÁLISIS DEL DISCURSO: DEL POSTMODERNISMO A LAS RAZONES PRÁCTICAS
}

\author{
Luis Enrique Alonso
}

Universidad Autónoma de Madrid

\author{
Javier Callejo
}

Universidad Nacional de Educación a Distancia

\section{RESUMEN}

La intención del artículo es analizar críticamente diferentes escuelas postestructuralistas de análisis del discurso en su contribución a la formación del fenómeno cultural llamado postmodernidad. Revisando así una serie de líneas de trabajo en el ámbito del análisis del discurso postmoderno - y que se han resumido en tres tendencias: intertextualistas, constructivistas y deconstruccionistas-, se trata de evaluar sus posibilidades reales de contribución al conocimiento social, llamando también la atención sobre el peligro de confundir toda práctica de análisis e interpretación de textos y discursos con un pretendido estadio postmoderno de la investigación social. Finalmente, se apuesta por un análisis sociológico de los discursos como reconstrucción crítica, ligada, fundamentalmente, a la situación y a la contextualización histórica de la enunciación; interpretación basada, por tanto, en la fuerza social y en los espacios comunicativos concretos que arman y enmarcan los discursos de los actores concretos como prácticas significantes.

"Porque alli donde parece que ya no hay nada ni nadie, en la frontera última, aparece el otro, aparecemos todos.»

Octavio PAZ (1974: 113).

"La idea de construir un laberinto, un edificio para que quien entre en él se pierda, es una idea rarisima."

Jorge Luis Borges, en Bravo y Paoletti (1999: 116). 
"De esta manera, vuelven a emplearse el estrecho empirismo y el relativismo cultural para legitimar un proyecto que, con el nombre de posmodernismo, asocia una conceptualización conservadora con una escritura estetizante."

Marc AugÉ (1995: 54).

\section{INTRODUCCIÓN ${ }^{1}$}

Postmodernidad y postmodernismo no son ni palabras ni conceptos nuevos para la tradición cultural hispana. Estos términos que hoy nos resuenan conectados a la renovación —o quizás la desorientación- del pensamiento occidental de los años ochenta y noventa, fueron ya profusamente utilizados por los escritores hispanoamericanos de los años diez y veinte —en una fusión de movimientos vanguardistas que atravesaría el ultraísmo, el futurismo y el creacionismo simbolista - para armar lo que era su frente de oposición a la literatura y el ensayo derivados del humanismo sobredramatizado de la generación del noventa y ocho, o de la imaginería ingenuista y vitalista del primer modernismo colorista. Así, la reivindicación del valor generativo de la metáfora, de la autonomía de la forma, del intelectualismo extremo, de la imposible separación entre lo real y lo imaginario, o de la compleja multideterminación del azar, etc., fueron ideas que, asociadas a aquel postmodernismo arcaico, ya se pusieron en juego en esa época y que hoy cobran especial actualidad al ser moneda de curso corriente del repertorio postmoderno convencional, usadas hasta la saciedad por cualquier autor que quiera situarse en la que es considerada la sensibilidad cultural dominante de nuestro fin de siglo. Hasta alguno de los autores de esa postmodernidad arcaica, como es el caso de Jorge Luis Borges —allí todavía de la mano de la monumental presencia literaria del más raro, erudito y casi maldito personaje de nuestra literatura reciente, el hace poco todavía olvidado y hoy casi idolatrado Rafael Cansinos Assens-, se han convertido en personajes fetiche del postmodernismo de hoy y, de la misma manera, hasta alguna de las críticas que ya se les realizaron entonces a aquel confuso y confusionista movimiento - su excesivo reaccionarismo, elitismo, conservadurismo, formalismo, nihilismo, etc. - se siguen repitiendo hoy sin demasiados problemas en la transposición ${ }^{2}$.

De esta manera, como ha señalado Umberto $\mathrm{Eco}^{3}$, existe una irresistible

Agradecemos las sugerencias de los evaluadores de la REIS, buena parte de las cuales han sido recogidas en el texto.

2 Sobre el tema del postmodernismo literario español e hispanoamericano de los primeros decenios del siglo XX y su influencia sobre visiones teóricas actuales, véanse Del Río (1996: 447524) y Yurkievich (1996). Perry Anderson (1998), en un interesantísimo trabajo, rastrea en los orígenes del concepto de postmodernismo y en sus usos más antiguos sin olvidar sus raíces hispanas e hispanoamericanas.

${ }^{3}$ Este diagnóstico se encuentra en Eco (1988: 658-659), y una aplicación para temas actuales en Eco (1998). 
vinculación entre el postmodernismo y el manierismo, hasta acabar diagnosticando el mismo Eco que los postmodernos son los manieristas de nuestra época o, quizás, los manieristas de todas las épocas. De hecho, este movimiento cultural, cuando arranca en la arquitectura, a final de los años setenta, trata de acabar con la dictadura del racionalismo y el funcionalismo centrales en el pensamiento moderno, así como con la fe en el progreso, la técnica y la historia lineal, y sustituir todo este síndrome de convenciones e instituciones naturalizadas por el pensamiento normalizador occidental por una nueva sensibilidad basada en el eclecticismo, la ironía, lo ameno, lo débil, lo hipercomplejo, lo mínimo y, sobre todo, por la ausencia de toda pretensión de encontrar una razón que pueda ser definida fuera del relativismo más extremo ${ }^{4}$.

De cómo este movimiento fundamentalmente estético se ha ido convirtiendo en central en el pensamiento occidental actual y de cómo este postmodernismo elitista, nihilista y apocalíptico se complementa sin dificultad con el más agresivo neoliberalismo economicista y mercantilizador hasta convertirse en una especie de adorno formal del individualismo propietario actual, mucho se ha escrito y mucho queda por escribir ${ }^{5}$. Quizás ya la fuerte pretensión esteticista y retórica de sus propuestas indique mucho de su triunfo y su conversión en moda. Pero lo que aquí nos va a ocupar es otra cosa, mucho más modesta, como es llevar a cabo una primera evaluación de recepción de lo postmoderno en las prácticas de investigación sociológica y especialmente en lo que, no sin problemas terminológicos de todo tipo, llamamos sociología cualitativa. Recepción que ha supuesto, como era previsible en este tema, una buena dosis de confusión de concepto, de falsos descubrimientos y de atribuciones equivocadas, lo que ha llevado a que se venga realizando una especie de asimilación dudosa, y desde luego abusiva, entre herramientas intelectuales que se encontraban desde hace decenios entre los útiles interpretativos de los saberes sociales no positivistas (la hermenéutica, el análisis del discurso, las prácticas dialógicas y conversacionales) y una suerte de postmodernismo imperialista que carga con sus valores asociados todo lo que toca.

De esta manera, tanto observado de una forma positiva y natural ${ }^{6}$ como

${ }^{4}$ El libro de arranque sobre el postmodernismo en la arquitectura es el de Jencks (1987); merece la pena consultar las observaciones sobre la estética postmoderna que se encuentran en Ripalda (1996) y en Connor (1996). Precisamente leyendo una valoración de la arquitectura postmoderna — la que realiza el arquitecto mexicano Jesús Rábago (1995: 171)—, nos encontramos con una presentación del tema directa y sugerente: "Las preocupaciones de la postmodernidad parecen válidas, no asi sus propuestas que tienden más a mostrar caprichos absurdos que proyectos pertinentes», y Habermas (1994) arranca en un sugerente ensayo sobre la arquitectura postmoderna para criticar la política de la postmodernidad y con una evaluación muy parecida a la del autor anterior.

5 Sobre las relaciones entre el postmodernismo cultural y el neoconservadurismo que arranca en los años ochenta pueden verse los trabajos recogidos en dos de las más completas revisiones sobre el tema, como son las de Nicholson y Sheidman (1995) y Berger (1998).

6 Ejemplos típicos de atribución del carácter postmoderno a cualquier enfoque discursivo/interpretativo en diferentes disciplinas son los de Howarth (1997), Collier, Minton y 
presentado con alarma, rechazo y escándalo ${ }^{7}$, se vienen haciendo analogías frecuentes entre el uso de prácticas de interpretación discursiva y condición postmoderna. La verdad es que el giro lingüístico e interpretativo de la filosofía de los últimos años había dejado el terreno abonado para los «excesos» postmodernos. Así, de los juegos del lenguaje hemos pasado al poder absoluto del texto, de la búsqueda del sentido a la quiebra de los metarrelatos, de la apreciación de lo concreto a la voluntad de fragmento, y de la búsqueda del diálogo y el consenso como forma pragmática de verdad a la búsqueda del disenso y el reconocimiento del poder como único criterio de definición de la realidad ${ }^{8}$.

Tomando prestados unos cuantos tópicos discursivos de los desarrollos últimos de las ciencias experimentales diversas (caos, fractalidad, catástrofe, azar, borrosidad, bifurcación, estructuras disipativas, etc.) e incrustándolos en lo que es el sustrato fundamentador e impulsor del movimiento postmoderno: la semiótica postestructuralista, un curioso fantasma recorre así — quizás desmigajándola - a la hermenéutica contemporánea, reforzando hasta casi hacer único el lado más subjetivista, nihilista y relativizador de la interpretación, hasta convertir a ésta en otra micronarración sin pretensión ni de saber, ni de verdad, sin esencia, sustancia o situación que no sea explicada por los propios contextos — textuales y lingüísticos — de un lector mínimo y minimalista atravesado por contingencias, ambigüedades y diferencias?

Pero esta especie de cierre discursivo - y, sobre todo, textual- de las (anti)interpretaciones de filiación postmodernista deja fuera demasiadas cosas como para satisfacer la mínima sensibilidad sociológica; su centramiento en la retórica, su teoricismo e intelectualismo y su escasa referencia a cualquier uso o práctica que no sea estrictamente lingüística, por no decir estrictamente literaria, hacen que el antisociologismo latente o manifiesto de los planteamientos postmodernos salte casi a la vista. Y si bien tales planteamientos nos pueden aportar intuiciones, materiales de reflexión e iluminaciones particulares, al ser realizados en última instancia, en ese "modo postmoderno», desde el supuesto

Reynolds (1996: 486-533) y Waters (1994: 206-217). Por fin, Denzin y Lincoln (1994: 11), en la introducción de su conocido manual sobre métodos de investigación cualitativa, acaban por hacer unas etapas del pensamiento sociológico cualitativo coronadas por el postmodernismo, considerado como culminación y máximo desarrollo de una especie de "revolución permanente» antipositivista.

El más ilustre ejemplo de esta actitud escandalizada, y tal vez, según nuestra opinión, desenfocada, es el de Gellner (1994). Daniel Bell (1997), desde su habitual línea neoconservadora, pero siempre cultísimo y atentísimo a las polémicas intelectuales de su tiempo, abunda matizadamente en esta postura — no por casualidad, en uno de los momentos más intensos de su trabajo echa mano de Gellner-, aunque de manera mucho más flexible.

8 Evidentemente, el gran teórico de la postmodernidad como movimiento cultural es Lyotard (1984); versiones mucho más matizadas, reflexivas y críticas son las de Harvey (1989), Lash y Urry (1996) y Lash (1997). Por fin, una deliciosa introducción humorística se encuentra en Lemert (1999), donde acaba asegurando que postmodernidad es «todo menos lo que tú te piensas».

9 Como resumen solvente de todos los tópicos sobre la postmodernidad y el postmodernismo, Smart (1992), Lyon (1996) y Bauman (1993). 
de un decodificador absoluto (aunque sea presentado como el «lector sin atributos»), también oscurecen y emborronan gran parte de lo que, desde muy diferentes escuelas y tradiciones de pensamiento social (teoría crítica, etnometodología, interaccionismo simbólico, pragmática, fenomenologías hermenéuticas varias, dramatología, etc.), había acabado conformando una sociología cualitativa o sociohermenéutica que hace de los actores y grupos sociales, y de sus prácticas — concretas, complejas, completas-, no los pretextos para la interpretación, sino los productores y receptores del sentido.

Sentido que no es sólo una arbitrariedad más de quien interpreta, sino que se incorpora de manera pragmática a las acciones de los sujetos sociales. Interpretar, así, no es inventar el sentido, sino reconocerlo en el conjunto de relaciones y poderes que enlazan a los grupos sociales y, por lo tanto, (re)construirlo según, también, la posición social del investigador. Las páginas que siguen tratan precisamente de deshacer entuertos y clarificar situaciones, tratando de hacer resaltar que quizás la falta de modestia que, en el fondo, ha supuesto toda la confusión postmoderna, más que enterrar definitivamente al positivismo, quizás le haya dado nuevas alas al sumergir la labor de la crítica en una profunda sima asocial donde "todo vale» y donde, por tanto, se instituye el análisis del discurso sobre la máxima de «todos los gatos son pardos», cosa que más que reforzar la atención sobre lo discursivo lo disuelve por saturación; sus términos, el postmodernismo tiende a la entropía discursiva, quedando todo en una confusión socialmente estéril. Como se dice en una reciente y muy completa evaluación de lo que el postmodernismo nos ha dejado — realizada expresamente ya después y «más alla» del giro cultural postmoderno (Bonnel y Hunt, 1999: 25)—, al tenor de los tiempos que hemos vivido nos deberíamos decidir por un estilo de pensamiento algo más modesto y menos ambicioso, rechazando posiciones que intenten o bien explicarlo todo (como el positivismo y las escuelas marxistas más mecanicistas algún día tuvieron la esperanza de hacer) o bien no explicar nada, como los postmodernistas pretenden al presentar un rechazo absoluto a la idea de explicación en sí misma.

\section{CLASIFICANDO LA CLASIFICATORIA POSTMODERNIDAD}

El enfrentamiento a la postmodernidad aparece bajo un fuerte impulso clasificatorio. Foucault, referencia principal al hablar de la postmodernidad, inicia Las palabras y las cosas, brillante ejercicio clasificatorio en sí mismo, con una clasificación de Borges en la que se incluyen los seres imaginarios. David Lyon (1996) se ve en la necesidad de clasificar autores para desenredar la madeja de los significados de la postmodernidad y explicarla a un público supuestamente inexperto. La propia postmodernidad es una pauta clasificatoria que dice lo que se ha de poner en la tradición, en la modernidad y en lo que no es ni modernidad ni tradición. Por lo tanto, parece conveniente realizar una mínima clasificación como inicio de un trabajo sobre lo que hace - $-\mathrm{y}$ deja 
de hacer - esa entidad imaginaria ${ }^{10}$ que es la propia postmodernidad. Una entidad imaginaria condenada a condenar lo existente, ya sea crítica o fatalmente, desde una supuesta tendencia hacia el futuro.

Las clasificaciones de la postmodernidad, que aquí se exponen de manera previa, tienen por eje principal la relación con el discurso, centro metodológico de este trabajo destinado a realizar dos observaciones: a) recoger críticamente lo que se entiende por análisis (postmoderno) del discurso y sus aportaciones al análisis sociológico; $b$ ) romper con la actual identificación, especialmente en el ámbito anglosajón, entre análisis del discurso y análisis postmoderno del discurso, apuntando las posibilidades de otras formas de análisis de discursos más cercanas a los intereses concretos de la investigación sociológica $^{11}$.

Es tal la identificación entre postmodernidad y discurso que se ha llegado a constituir el propio término de discurso como el portador de un programa teórico completo que empieza con Lévi-Strauss y tiene como principal paladín a Foucault (Frank, 1988), a lo que se podría añadir la figura de enfant terrible de Derrida. Así, a pesar de las diferencias entre postmodernismo y estructuralismo, la linguiística y el análisis del discurso sucumben a los encantos estructuralistas (y postestructuralistas) en la crisis de la postmodernidad, como, en términos de Lecercle (1990), una especie de regreso de lo reprimido. Si bien es verdad que si algo caracteriza al postmodernismo es, desde el mismo Lyotard (1984), el hecho de situar todo problema en términos de "narratividad» o "discurso", es evidente que no todo problema sociológico puede resolverse según los esquemas del análisis del discurso propuesto por los postmodernos ${ }^{12}$.

En el análisis postmoderno del discurso, podemos encontrarnos, al menos, tres campos diferentes:

- Analistas de discursos producidos en situaciones empíricas que, casi siempre siguiendo la estela de Foucault, Derrida, etc., cabe considerar postmodernos o postestructuralistas. Es el más cercano a la discusión metodológica. También, el más cercano a lo que hacen los sociólogos: capturar discursos sociales para saber sobre las relaciones sociales.

— Analistas de «fenómenos postmodernos», definiendo como tales las que

${ }^{10}$ Consideración de la postmodernidad como entidad imaginaria por dos razones. En primer lugar, por dirigirse al imaginario del futuro. En segundo lugar, por la dificultad para concretarla en un campo definido. Cuanto más se desciende a los campos concretos, más difícil es encontrar quienes se autodefinan como postmodernos. Para el caso de la teoría social, véanse las dificultades encontradas por Kellner (1990).

11 Las limitaciones de extensión del trabajo nos conducen a acentuar las críticas sobre las propuestas analíticas enfocadas y, en especial, los obstáculos encontrados para su proyección directa en la investigación sociológica. Ello no es sinónimo de que no se puedan encontrar aportaciones de relevante interés en las mismas, que pueden recuperarse en futuros diálogos interdisciplinares.

12 Una evaluación separada de postestructuralismo y postmodernismo para el análisis sociológico se realiza en Alonso (1998). 
se encuentran en la producción cultural que parece «abrir una nueva era», casi siempre en clave de ficción: los que analizan los cyborgs y todo lo que tiene que ver con las nuevas tecnologías y la cultura del simulacro, el mundo de lo "postreal» y demás, a lo Baudrillard (1996). Lo que suelen hacer estos autores es generalizar a la sociedad, como lógica general de la sociedad o tendencias sociales, lo que pueden considerarse aspectos que conciernen a exquisitas minorías. La concepción del discurso puede alcanzar un papel central, como en el caso de Mitra (1999), para quien el discurso es el exclusivo conformador de las denominadas comunidades en Internet.

- Un campo intermedio, el de quienes, fundamentados en el papel dominante de los medios de comunicación, analizan el discurso de éstos como si los mensajes fueran masivamente entendidos tal como los expone el intérprete. Esto no sería nada postmoderno si no se incluyera algo cercano al segundo campo, como es la afirmación de que no hay diferencia entre el mundo de los medios y el de la ficción y el de la realidad, de manera que ambos se entrecruzan, lo que legitima la observación de los discursos de ficción como si fueran realidad. Se parte de un acontecimiento, por ejemplo: la crítica que Quayle hace a "Murphy Brown» (personaje de ficción) por querer ser madre soltera y que esta crítica fuese aceptada como real, con sentido, y no fuera recibida con escándalo por referirse a un personaje de ficción. Con tal justificación se analizan, por ejemplo, las series El show de Mary Tyler Moore y Murphy Brown para estudiar el modelo de organización vital que se está desarrollando en Estados Unidos $^{13}$. De esta manera, tienen otro de los rasgos de los analistas postmodernos: el no salir de los discursos, aun cuando, en este caso, sean los discursos de ficción.

Como puede verse, no es una clasificación excluyente, pues caben aportaciones que se encuentren entre un campo de analistas y otro o que intentan articulaciones de varios campos ${ }^{14}$. Pero, para empezar, puede valer. Dado su carácter «metodológico», el trabajo se va a centrar en los "primeros postmodernos».

Los analistas de discursos empíricos con la categoría de postmodernos pueden, a su vez, ser clasificados en:

${ }^{13}$ Véase Michèle Browing, Eye of the camera: An exploration of organizational life as protrayed on television (http://www.agsm.ucla.edu).

${ }^{14}$ Así, por ejemplo, cabe realizar análisis del discurso - del primer grupo- tomando los textos, que no son de ficción, como si lo fuesen. Es uno de los experimentos que principalmente caracteriza a la antropología postmoderna (Reynoso, 1991; Clifford, 1995). Incluso, uno de los principales inspiradores del análisis postmoderno de discursos, Foucault, define sus textos como textos de ficción: "me doy cuenta que no he escrito más que ficciones. No quiere, sin embargo, decir que esté fuera de la verdad. Me parece que existe la posibilidad de hacer funcionar la ficción en la verdad; de inducir efectos de verdad con un discurso de ficción, y hacer de tal suerte que el discurso de verdad suscite, "fabricase", algo que no existe todavia, es decir, "ficciones". Se "ficciona" historia a partir de una realidad politica que la hace verdadera, se "ficciona" una política que no existe todavía a partir de una realidad histórica» (Foucault, 1992b:162). 
- Intertextualistas: utilizan a Foucault como precursor metodológico y ocasionalmente lo articulan con Bajtin. Sorprende la filiación directa de los intertextualistas con Foucault, muy superior a su conexión con la del lingüista y crítico literario ruso Mijail Bajtin. No cabe duda de que en el autor francés está presente la intertextualidad, pudiéndose ir desde la descripción del análisis como puesta en relación del documento con la masa de documentos (Foucault, 1992a: 14) hasta sentencias como: "todo discurso manifiesto reposaría secretamente sobre un ya dicho, y que este ya dicho no sería simplemente una parte ya pronunciada, un texto ya escrito, sino un "nunca dicho", un discurso sin cuerpo, una voz tan silenciosa como un soplo, una escritura que no es más que la cruz de su propio trazo» (Foucault, 1992: 36). Hasta qué punto los intertextualistas (postmodernos) se acercan a esta concepción — secreta, un tanto mística, pero analíticamente potente, como el propio Foucault se encargó de mostrardepende de cada caso concreto. Aun cuando la concepción de intertextualidad puede variar enormemente de un analista a otro, es el concepto fetiche que une a diversos autores, conduciéndoles, en la mayor parte de los casos, a encontrarse bajo la categoría de postmodernidad.

- Constructivistas: aquí la utilización de Foucault, articulada especialmente con la etnometodología, viene dada por la consideración de éste como precursor de la afirmación de que las ciencias sociales construyen su objeto en su discurso, de manera que la relación entre discurso y poder es fundamentalmente epistemológica puesto que señalar algo como observable ya es construirlo. Puede servir de aclaración el que mientras los intertextualistas beben principalmente del Foucault de La arqueología del saber y El orden del discurso, los constructivistas lo hacen de la propuesta existente en Las palabras y las cosas.

- Deconstructivistas: siguen la apuesta de Derrida de enfrentamiento crítico a los discursos del saber, es decir, a los discursos producidos principalmente en los ámbitos académicos. Derrida se ocupó especialmente de deconstruir el discurso de la tradición filosófica. Deconstruir es el verbo que, utilizado por este autor, cuesta entender, salvo la evocación de bull-dozer tirando edificios y cierta apuesta hipercrítica, siendo una de las bases para que la obra de este autor haya sido tachada de irracional ${ }^{15}$. Deconstruir otras disciplinas es el objetivo de buena parte de los analistas de discursos de esta corriente, debiéndose reconocer que, entre las ciencias sociales, la antropología es la que se ha llevado la mayor parte de las críticas, pues tal vez sea la menos directamente relacionada con ejercicios operativos — comparándose con la economía o la sociología.

15 Habermas, en el ámbito del discurso filosófico, o Reynoso, en la aplicación de estas propuestas a la investigación antropológica, subrayan la irracionalidad derridiana: "La deconstrucción fue, en su origen, un método para recusar y destruir argumentativamente pero sin razonar, es decir, sin incurrir en los dictámenes de la argumentación racional. Pero ¿cómo es eso posible?» (Reynoso, 1991: 21). 


\section{UN MODELO DE ANÁLISIS INTERTEXTUALISTA}

Entre quienes directamente abordan la relación entre lenguaje y sociedad, la figura de Norman Fairclough es de especial interés para los objetivos de este trabajo por tres razones. Por un lado, su lugar fronterizo entre concepciones modernas, especialmente las que siguen a Marx, y concepciones postmodernas, radicándose aquí: las continuas referencias a Foucault, el reconocimiento del "giro lingüístico» como postmoderno (Fairclough, 1989: 3) y la propuesta de análisis apoyado en la intertextualidad. Por otro lado, por la atención que este autor presta a la representación de los procedimientos prácticos de análisis del discurso. Además, tales procedimientos se proyectan sobre ámbitos discursivos - tecnologías discursivas las denomina el autor, en claro seguimiento de Foucault - tan próximos y postmodernos como la publicidad —en cuanto al lugar protagonista en que es colocada-, considerándola como la principal fuente de producción del consenso en el capitalismo avanzado (Fairclough, 1989: 3637). Por último, se comparten bastantes puntos con el autor y algunos de sus seguidores más directos ${ }^{16}$, especialmente el enfoque — directamente emparentado con la teoría crítica de la sociedad- que se asume en el planteamiento de la investigación; tal base común obliga a descender suficientemente en el análisis a aspectos metodológicos concretos y a asumir, como si fueran autocríticas, algunas de las críticas que aquí se vierten.

Su presupuesto principal, desde las iniciales páginas de algunos de sus trabajos (Fairclough, 1989), es la concepción del lenguaje como productor o reproductor de las relaciones de poder en la sociedad, aunque siempre acompañada de la advertencia de evitar la reducción del poder al lenguaje. El lenguaje es un medio para producir consenso que, a su vez, es uno de los dos principales respaldos del poder. El otro es la violencia física. Pero, siguiendo al autor, también el lenguaje puede ser un instrumento para la emancipación —entendida como eliminación de las relaciones de poder, lo que no deja de ser una simple concepción de las mismas- siempre que sea un lenguaje resultado del análisis de la actuación opresora del lenguaje. El discurso producido de su análisis del discurso de los opresores se "transforma» en arma para el cambio de las relaciones de poder, al hacer conscientes a los subordinados del poder ejercido a través del discurso. Para ello, se prefigura, más fantasmal que realmente - especialmente en el ámbito educativo-, la figura de un receptor de su discurso analítico para cambiar otros discursos.

Para Fairclough, el análisis de los discursos, especialmente destacando su carácter intertextual, en cuanto discursos «realmente» extraños y ajenos a los subordinados utilizados para la opresión, produce conciencia (Fairclough, 1997). Parece que la conciencia es ya parte del cambio. No obstante, una pregunta del mismo Foucault es aquí pertinente: “¿Hay ruptura histórica entre la

${ }^{16}$ Con Luisa Martín Rojo, a quien puede considerarse seguidora de esta línea de análisis del discurso, se han realizado varias investigaciones (Martín Rojo y Callejo, 1995a, 1995b). 
edad de la represión y el análisis crítico de la represión" (Foucault, 1980: 18). Foucault no intenta ser moderno y postmoderno a la vez, no intenta partir de un sujeto generado en los discursos para recuperar después un sujeto que produce discursos.

Siguiendo a Bourdieu (Fairclough, 1989: 41), su propuesta de análisis crítico del discurso se destina a hacer conscientes a las clases subordinadas -entre las que sitúa a los alumnos frente al profesor- de lo que hacen, pero no tiene discurso. Entonces, la pregunta es: ¿qué análisis del discurso puede hacerse cuando no hay discurso? Parece que el análisis se dirige entonces hacia la situación en la que se produce el discurso, es decir, en la que se producen otros discursos distintos a los que «deberían producirse». En el loable intento de articular posiciones modernas, que parten de la idea de un sujeto, estructurante, como son las del mismo Bourdieu o de Giddens, autor que también refiere, con posiciones postmodernas, como las derivadas de la lectura de Foucault, donde el sujeto es producto de sus palabras (Fairclough, 1989: 104), es donde la claridad de su matriz teórica se quiebra, pues parecen posiciones difícilmente articulables. Esto, en el caso de sus análisis concretos lleva a, por ejemplo, admitir, por principio, la creatividad de los receptores y a hablar de interacción, aun cuando sólo sea con el proceso de interpretación; pero los receptores mismos desaparecen de las muestras de análisis que ofrece.

Más allá de sus ligazones teóricas ${ }^{17}$ y valores enarbolados, es de agradecer a Fairclough su compromiso con la muestra concreta de su práctica como analista del discurso, inscribiendo su propuesta en investigaciones empíricas. Es en tales procedimientos empíricos donde incorpora el concepto de intertextualidad.

En la fase descriptiva del análisis aparece la intertextualidad en el caso de sentencias negativas, pues, entonces, parecen inscribirse en un discurso que las precede (Fairclough, 1989: 125). Esta utilización de la intertextualidad como un instrumento del que son conscientes los individuos es una de las características fundamentales en la propuesta de Fairclough. Lo intertextual queda como una especie de matriz de trozos de discursos ajenos, que los sujetos - insertos en el lado del poder - utilizan a la manera de las piezas de un mecano para construir sus propios discursos. El propio discurso de los sujetos queda configurado como un bricolaje de discursos ajenos, es decir, no propios. Estos materiales, como cuando se presenta el ejemplo de la descripción arquetípica de la boda de Sarah Fergurson y el Príncipe Andrés de Inglaterra, quedan reflejados como la imposición de un conocimiento previo en un campo. Se selecciona, por parte de los medios de comunicación, una parte de este campo y se impone, quedando ocultas las supuestas otras partes del campo. Lo intertextual queda como un ocasional instrumento al servicio del poder capaz de imponer

${ }_{17}$ Algunas tan discutibles como la misma definición de poder, pues ésta queda como la capacidad para mantener una estructura o relación de dominio. Definición un tanto tautológica, pues resulta que el poder es la capacidad de mantener el poder. 
discursos ajenos en los receptores. No como algo estructural, requerido para la propia circulación de los discursos, para que éstos sean recibidos.

Siguiendo su presencia en el nivel de lo manifiesto, en el análisis del thatcherismo que presenta Fairclough (1989), lo intertextual toma las características de interesada respuesta a los oponentes. Como veladas referencias a tales oponentes. Como algo relativo a las tácticas de los agentes del poder y no como elemento intrínseco a los discursos, especialmente para que sean recibidos. Así, acusa a Thatcher de populismo, como arma particular de esta política conservadora, por decir lo que la gente quiere oír, que es lo que, por otro lado, Fairclough hace con su lector, lo que tal vez hagamos todos, jugando en la intertextualidad constantemente, en el juego de presupuestos y evocaciones comunes. Consideramos la concepción de Fairclough de intertextualiad muy naïf y evidente. Se trata de una intertextualidad manifiesta. Sin embargo, la propuesta de Bajtin (1989) es más potente: sitúa todo hablar, todo discurso, en diálogo con otros discursos, de tal manera que en todo discurso están presentes los discursos de los otros, aunque no se ponga en boca de otros o veladamente se haga referencia a los oponentes en el diálogo.

En la línea intertextual propuesta por Fairclough se ve a un sujeto rebotado de un texto a otro sin llegar al final, al significado del texto. Entonces, como señala Culler (1998: 32), la intertextualidad se limita a ser un análisis de los presupuestos, de los textos previos, y no un análisis de las presuposiciones que producen el texto, como propone este mismo autor ${ }^{18}$.

Siguiendo con esta concepción de la intertextualiad, merece la pena detenerse en un análisis de discurso concreto realizado por Fairclough (1997).

En la observación de distintos mensajes expuestos en instituciones académicas, se trata sobre todo de carteles en la Universidad, el analista británico observa la presencia de expresiones que parecen propias de la publicidad convencional. Para desentrañar el asunto hace uso del concepto de intertextualidad, entendido como la búsqueda táctica de los ecos de otros textos ${ }^{19}$. En el caso referido, se trata del análisis del eco del discurso publicitario-marketing en el discurso académico ${ }^{20}$. Un análisis que lleva a la conclusión de que el lenguaje se está convirtiendo en una mercancía ("the talk is part of the goods»), como parte de la colonización del mundo de la vida por los sistemas del dinero y el poder, en términos de eco habermasiano utilizados por el propio analista. Concluir que, a las alturas históricas del capitalismo en que nos encontramos,

${ }^{18}$ Un interesante aspecto del trabajo de Culler (1998) reside en la concepción del análisis intertextual como aquel que tiene en cuenta los presupuestos del receptor, es decir, lo que hace que un discurso se acepte, total o parcialmente, lo que exige observar al receptor.

19 «El análisis intertextual identifica articulaciones de géneros y discursos [a diferencia del análisis lingüístico que] muestra cómo tales articulaciones se realizan en los sentidos y textura del texto" (Fairclough, 1997: 291).

${ }^{20}$ En una película de Godard se veía cómo sus personajes, para sus relaciones cotidianas, hablaban como si fuesen anuncios de publicidad, lo que venía a significar la presión del lenguaje publicitario sobre la vida cotidiana. 
que todo se convierte en mercancía, que todo se evapora en el aire ${ }^{21}$, es un ejercicio de cierta ingenuidad, $y$, por otra parte, es dar por supuesto que, antes, en el lenguaje y la vida en general no estaban presentes ni la política ni la economía, es una visión bastante compartimentalizada de la realidad social. Sin embargo, no se pregunta por las condiciones que posibilitan la producción y circulación de un discurso que "vende la Universidad» como jabones y que, sobre todo, asimila esta institución pública a las empresas privadas. Se escandaliza de la invasión de un lenguaje (académico) por otro (publicitario), por la pérdida de pureza de un lenguaje; pero no por las condiciones sociales que hacen que ya casi nadie se escandalice por este "nuevo tipo de discurso en las instituciones públicas». El problema no está en las características del discurso, sino en que un discurso de tales características circule y se haga dominante.

Las intenciones de Fairclough, especialmente cuando propone un programa de análisis de corte dialéctico (Fairclough, 1995: 34, 55), son aceptables. Sin embargo, los resultados concretos de sus análisis en casos específicos y, sobre todo, la concepción de intertextualidad son discutibles desde la perspectiva de una sociología que busca operar en lo específico. Algo que no se propo$n e^{22}$, pues, en principio, su objetivo es que el análisis de los discursos (mediáticos) sirva de barómetro del cambio sociocultural (Fairclough, 1995: 52) o como base para una educación más crítica (Fairclough, 1989). Pero más acá de esto, el problema es que las intenciones dialécticas no se ven reflejadas en los análisis concretos que presenta, como el de la serie televisiva Vigilante, pues ¿dónde está la dialéctica cuando el análisis permanece en cómo el discurso público, de lo público, tiene que incorporar el discurso de lo privado para introducirse en el ámbito doméstico? ${ }^{23}$ Es más, en los análisis observados de este autor se deriva constantemente que el "orden del discurso", concepto que Fairclough toma de Foucault, ordena la comunidad. Su preocupación es, más allá de las intenciones dialécticas: observar la vida propia de los discursos, hablando de la transformación de textos a través de "cadenas intertextuales" (Fairclough, 1992) y "cómo las variaciones en el lenguaje y las prácticas discursivas en los media constituyen el cambio social y cultural» (Fairclough, 1995: 29).

${ }^{21}$ Utilizando la famosa frase de Marx y Engels —o seguramente de su primer traductor en inglés- en el Manifiesto, y después, aplicada al mundo de la estética moderna por Marshall Berman (1988) en uno de los más deslumbrantes ensayos culturales de los últimos veinte años.

22 Cuando la sospecha de la ausencia de dialéctica sociedad-lenguaje en su análisis crece, Fairclough adelanta los argumentos de defensa: "no escribo como un sociólogo», nos dice (Fairclough, 1995: 62). Llevados a este extremo, se pierden las diferencias con otro tipo de propuestas analíticas en origen tan distantes como las que puede presentar el lingüista holandés T. A. van Dijk (1985).

${ }_{23}$ De hecho, la intertextualidd termina como un ejercicio de creatividad (Fairclough, 1995: 61); pero la intertextualidad ha estado casi siempre entre las fuentes de la creatividad: ¿puede ser de otra manera? Con respecto a una de las conclusiones que atraviesa los últimos análisis publicados por Fairclough, la invasión del discurso de lo privado del discurso de lo público, se echa en falta la ausencia de un mínimo comentario de algo que, en apariencia, parece presentar una tendencia inversa, como es la existencia de publicidad — discurso privado de la mercancía - con referencia a asuntos públicos, como la ecología (anuncios verdes), la solidaridad, etc. 
Siguiendo al Foucault que hace hincapié en los infranqueables dispositivos de poder, Fairclough concibe la producción discursiva como un dispositivo de control social: "Mi principal objetivo ha sido sugerir que las noticias (y lo mismo vale para, por ejemplo, los documentales) incluyen mecanismos para ordenar voces, subjetivarlas para el control social. El mero hecho de que una plétora de voces sea incluida en el tratamiento que hacen los medios de comunicación de masas de temas sociales y politicos no implica una ausencia de control, pues lo que es decisivo es el cómo están entretejidas, cómo están ordenadas unas con respecto a las otras" (Fairclough, 1995: 84). La intertextualidad no ha de verse como una carnavalesca pérdida de control, sino, al contrario, como un ejercicio de poder, de control social. Así, la conversacionalización de los discursos, una de las principales estrategias dialógico-intertextuales, es puesta bajo sospecha como una táctica del poder para entrar en la vida cotidiana de los individuos, sin que el poder pierda nada en tal acción. El poder siempre gana.

Para interpretar los textos de los medios como dispositivos de poder, se ve en la necesidad de dudar de la recepción. Lo que parece liberador o, al menos, más cercano a algunos sectores sociales, «realmente no lo es». Así, no parece aceptar las distintas (sociales) posibilidades de lectura, de interpretación (Fairclough, 1995: 16) más que como un aspecto complementario al análisis de la naturaleza del texto. Es más, en un análisis concreto como el que realiza sobre una publicidad de electrodomésticos de la marca Miele (Fairclough, 1989: 204) supone que sabe lo que el receptor va a interpretar.

Fairclough, al acentuar los tipos de discurso y la intertextualidad — con la victimización del discurso "colonizado»—, traiciona al Foucault que observa cómo son regularmente atravesados los distintos tipos de discursos por un orden, conformando unidad discursiva (Foucault, 1992a: 33 ss.). Mientras Fairclough idealiza los textos puros, para mostrar su mezcla —intertextualidad, según su concepción - en lo concreto, Foucault denuncia el cierre de, por ejemplo, el texto libro: "construido a partir de un campo complejo de discursos" (Foucault, 1992a: 34).

En el caso de Fairclough, parece perderse parte de la potencial riqueza metodológica que tiene la propuesta de intertextualidad en el mismo Foucault. Al convertirla en una ontología de acceso directo, más o menos fácilmente perceptible en los discursos como instrumento de la opresión, deja de operar como la obsesiva palanca analítica que pregunta a cada fragmento de un discurso analizado sobre sus presuposiciones, con qué otro discurso se encuentra dialogando y, por tanto, con qué otro discurso o discursos se encuentra en una relación asociativa o conflictiva. Hasta tal punto se diferencia que cabe pensar sobre la conveniencia de separar la intertextualidad con base foucaultina $-\mathrm{y}$, más aún, la de base en Bajtin— de la ofrecida por este autor. 


\section{RECONSTRUYENDO EL CONSTRUCTIVISMO POSTMODERNO}

Una de las acusaciones más relevantes en contra de las corrientes postestructuralistas es la centralidad que toman los textos, entendidos como lo escrito y - más específicamente- el texto como engranaje de significantes, frente a lo conversacional: "donde se engarzan la referencia y el significado" (Giddens, 1990: 273). No obstante, puede incluirse como propuesta de análisis postmoderna de discursos la realizada desde cierto constructivismo. Al menos, es reivindicada la tradición postestructuralista, como ocurre en Potter, autor en el que se apoya esta parte del trabajo.

Haciendo una interesante - y explosiva - mezcla con el Barthes, ya postestructuralista, de $S / Z$ y su análisis de la retórica realista, la etnometodología, la sociología de la ciencia de Gilbert y Mulkay y el Foucault de, principalmente, las epistemes y los efectos de verdad de Las palabras y las cosas y El orden del discurso, Potter (1996) puede considerarse un modelo singular de análisis postmoderno del discurso ${ }^{24}$. Categoría que no acepta.

En Barthes, Potter encuentra la construcción textual de la subjetividad (Potter, 1996: 76), lo que ya da idea del lugar que ocupa el sujeto como mero efecto del texto. El sujeto sólo aparece como enunciado. En el Barthes que analiza la retórica realista, Potter observa cómo la distancia descriptivista no es más que una táctica retórica para defender los propios intereses. Observación que proyectará desde la ficción, el análisis de un cuento de Balzac, al análisis de conversaciones. Nuevamente nos encontramos con la indiferencia entre hecho y ficción entre los postmodernistas (Potter, 1996: 88).

La etnometodología es la referencia para subrayar cómo los individuos pueden negociar sus identidades en la relación inmediata con los otros, como si pudieran elegir más o menos libremente tales identidades, según sus individuales intereses. Otra referencia es la sociología de la ciencia, para desembarazarse de lo empírico, pues "las particularidades empiricas no son lo importante» (Potter, 1996: 172). Lo importante es el análisis y el analista aplicado a descubrir los intereses de los otros y, por supuesto, a convencer al metaanalista o no se sabe bien a quién. Al fin y al cabo: "la verdad es sólo capacidad de convicción" (Potter, 1996: 4). El realismo queda como una cuestión de efecto del discurso (Potter, 1997). Para ello, la realidad se convierte en referencias a la realidad y éstas, después, en realismo, como si fuese una militancia obcecada, contraria al constructivismo o al relativismo.

Tal es el desprecio de lo empírico que las muestras empíricas que Potter presenta para ejemplificar su análisis son de una banalidad aplastante, desde las que van de fragmentos al uso etnometodológico-batesoniano hasta la supuesta deslegitimación del empleo de la estadística, al observar cómo quienes se encargan de presentar públicamente los resultados de los registros estadísticos

24 Una posición similar, en cuanto lectura constructivista de Foucault, se encuentra en Íniguez (1997). 
de muerte por cáncer maximizan o minimizan los mismos según sus particulares intereses. Es decir, un remake de la broma del medio pollo estadístico (media entre dos: uno tiene un pollo, el otro ninguno) le sirve como base para «demostrar» cómo la realidad es construida por la propia estadística.

Aun cuando se habla de construcción social, más bien parece tratarse de construcción lingüística. Hasta la cosificación de la mercancía, analizada por Marx, se traduce en términos de efectos del discurso, dejando a un lado el proceso socioeconómico. De cara a nuestro objetivo metodológico, interesa destacar cómo lo observable queda reducido a lo registrable lingüísticamente. Así, se plantea cómo el trabajo etnográfico ya no es posible sin una grabadora-cassette y sin transcripciones.

Vayamos a una aplicación concreta de su forma analítica. Potter mantiene

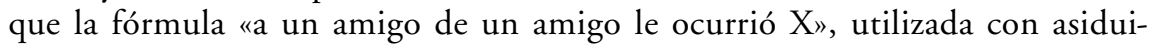
dad, es un mecanismo de defensa para que quien la pronuncie no sea preguntado después por las circunstancias concretas del acontecimiento. Así, según este autor, pueden circular acontecimientos estandarizados y de alcance global con una alta credibilidad. Conclusión que un mínimo de sentido común consideraría como débil, pues, precisamente, la fórmula "un amigo de un amigo» parece restar bastante credibilidad a lo que se dice. Si se cree o deja de creer es por el sentido que lo dicho pueda encontrar en los receptores. Pero Potter sólo tiene en cuenta los receptores como especulativos atribuidores de intereses a lo dicho por el otro (Potter, 1996: 110). Lo importante no es lo dicho, sino una mutilada capacidad de convicción autónoma del lenguaje. El lenguaje es capaz de convencer por sí mismo.

El mundo y, por lo tanto, las condiciones del lenguaje y, sobre todo, las condiciones de posibilidad de los discursos no existen. El mundo, nos dice el constructivista, "es una u otra manera como la gente lo habla, lo escribe y lo argumenta" (Potter, 1996: 98). Así, siguiendo los ejemplos propuestos por el autor, los esquimales diferencian distintos tipos de nieve porque «está en su lenguaje» y no porque se encuentren en unas condiciones de existencia que les conducen a una serie de prácticas que tienen en cuenta el estado de la nieve y que, por lo tanto, les lleva asimismo a unas específicas prácticas lingüísticas.

Siendo coherente con tal marco, la propia gente es un producto del habla, de la escritura, de la argumentación. A la metáfora del espejo —el lenguaje es un espejo del mundo-, el autor (Potter, 1996: 97 ss.) opone la metáfora de la construcción, lo que lleva a que el mundo sea un espejo del lenguaje. Es aquí donde la propuesta parece entrar en cierta contradicción, pues ¿qué son los intereses que se atribuyen a los individuos? ¿No son también efecto del discurso?

La propuesta de Potter, como ocurre con la mayor parte de la etnometodología, tiene interés en la medida que hace reflexionar sobre las situaciones inmediatas. En el caso de la investigación social empírica, ayuda a tener en cuenta cómo lo dicho por los participantes en una investigación -encuesta, entrevista o grupo de discusión, por ejemplo- puede estar condicionado por 
la relación que se origina en la propia situación (experimental) de investigación. En la medida que los participantes se perciban directamente vinculados con los posibles resultados de la investigación, habrá que tener más en cuenta este aspecto. Entonces están sus intereses por medio. Ahora bien, reducir el análisis de los discursos producidos en tales situaciones experimentales a la relación con la propia situación castra toda posibilidad de investigación sociológica, donde los participantes en un contexto inmediato lo son en cuanto representantes de sectores sociales en contextos más generales. Sería derivar el análisis hacia el situacionismo ${ }^{25}$.

\section{EXPRIMIR A FOUCAULT}

Como se ha dicho, buena parte del análisis postmoderno del discurso se autodefine tras la estela de la obra de Foucault. Pero ¿en qué Foucault se apoyan, dada la extensión y, sobre todo, lo polisémico de su obra?, ¿el hincapié que hacen los postmodernos en centrarse exclusivamente en los discursos es foucaultiano?, ¿qué análisis de discurso realiza este autor?, etc. Por supuesto, no es éste el lugar para responder a estas preguntas ${ }^{26}$. Sólo se quieren señalar dos hipótesis, que se reconocen enormemente discutibles:

a) Para Foucault, los discursos son un material del que parte el análisis de lo social y no un lugar de destino.

b) Más que un analista de discursos, Foucault es un analista de las nulas posibilidades de discursos para enfrentarse a los discursos que señala como dominantes, lo que ha provocado que haya sido reivindicado por buena parte de las minorías sin discurso.

Ambas hipótesis conducen a un Foucault menos postmoderno del que está en algunos de sus seguidores. Incluso, paradójicamente, a un autor moderno. Nos centraremos en la primera hipótesis. La segunda se encuentra desarrollada especialmente en su Arqueología del saber, ofreciendo lo que puede considerarse una metodología analítica para tener en cuenta las exclusiones sociales en los discursos y para pensar en las posibilidades que hacen imposibles los discursos

${ }^{25}$ En el ejemplo del tribunal que plantea Potter (1996, Extracto), la decisión del juez está entre la retórica del abogado defensor y la del fiscal. La credibilidad se fundamenta sólo en las capacidades retóricas de quienes exponen los hechos en la situación del juicio. Aplicado a la investigación sociológica, sería alcanzar las conclusiones sobre algún asunto o conflicto en función de las retóricas recogidas más brillantes, más efectivas, y no por el sentido que tengan.

${ }^{26}$ Como ya se señala en Alonso (1998: 152), la bibliografía sobre Foucault constituye ya una inmensidad oceánica. De carácter introductorio y como añadido a las obras que Alonso refiere en la nota 12 del capítulo 4, cabe destacar las de Gros (1996), Gabilondo (1990), Vázquez García (1995) y Marietti (1985), pues en todas ellas se presenta la concepción foucaultiana del discurso. 
excluidos, de manera que el análisis de tales discursos potenciales y excluidos pone en evidencia las condiciones concretas que favorecen la circulación de sólo un tipo de discursos, los que precisamente excluyen a los sujetos sociales que podrían mantener los discursos excluidos.

$\mathrm{Al}$ menos en una parte importante de los trabajos de Foucault está presente la concepción del discurso como una vía metodológica para el estudio de lo social. Una vía imprescindible: «si queremos estudiar el establecimiento y los efectos de la explotación capitalista, ¿con qué tenemos que habérnoslas?, ¿dónde la veremos traducida? En los discursos, entendidos en un sentido amplio" (Foucault, 1984: 163). Hasta llega a rechazar todo cierre discursivo: "En realidad no tendría sentido decir que sólo existe el discurso. Un ejemplo muy simple es que la explotación capitalista se realizó sin que su teoría hubiese sido jamás formulada directamente en un discurso» (Foucault, 1984: 162). La propia existencia de esta última sentencia, de aspecto defensivo, habla de la circulación de una interpretación del autor en clave de cierre discursivo. Pero, en cualquier caso, se trata de una defensa firme. Siguiendo sus categorías, puede decirse que Foucault está más interesado por responder a qué hace posible un discurso, cuáles son sus condiciones de posibilidad, que en averiguar las propias características del discurso.

Es el mismo Foucault quien señala que el verdadero acto de represión es convertir todo deseo en discurso, lo que puede proyectarse en otra sentencia: el verdadero acto de exclusión (de las relaciones de dominación) es convertir las relaciones de dominación y exclusión en actos discursivos. ¿ No se rebaja el horizonte de liberación, entendido como proyección práctica de la «voluntad de saber", reduciéndolo al discurso? Parece que se gestionan mejor discursos que otras prácticas concretas. Ante las denuncias sobre las características de un discurso, tal vez puede valer con una simple ortopedia discursiva o tecnología discursiva, siguiendo sus términos: control del discurso público sobre las relaciones entre clases sociales, etnias, razas, géneros, evitar la circulación de expresiones molestas o excluyentes. Basta con ser políticamente correcto. Es Foucault quien insiste en que el cambio de régimen de los discursos no significa directamente una mayor o menor represión/liberación, un cambio en la posición respectiva de los agentes, para seguir hablando con categorías políticas que, además, incluyen actores. Su corolario aplicado vendría a preguntarse por qué tantas denuncias sobre discursos, expresiones, razonamientos, sistemas filosóficos, etc., «machistas» o racistas no acaban con el «machismo» o el racismo; por qué el canto de liberación del feminismo, proyectado en todos los ámbitos, apenas parece liberar más que a aquellas mujeres que por su posición social están ya «liberadas». Seguramente la contestación a esta pregunta exige una mínima salida de los discursos.

En el caso de su estudio sobre la historia de la sexualidad, lo importante para Foucault no es tanto la caracterización del discurso del sexo, del que apenas da unas notas como "simple vuelo sobre la cuestión", sino el propio hecho de que existan tantos discursos sobre el sexo. El problema no es el discurso sobre el sexo, sino la concepción de la sexualidad en una sociedad que se 
esfuerza por registrarla en discursos, bajo la suposición de que ni la sexualidad ni las concreciones discursivas están fuera o por encima de la sociedad. Como ocurre en el caso de la locura (Foucault, 1979, 1994: 167 ss.), la sexualidad no existe más que en una sociedad. Por ejemplo, aplicando a Foucault en análisis de las relaciones entre los géneros, ¿no deberíamos preguntarnos sobre los procesos históricos y concretos que condicionan el "hecho discursivo», la "puesta en discurso" de la exclusión de las mujeres y la dominación de la mujer por el varón? Al postmoderno foucaultiano que le suene muy conservadora esta pregunta se le recomienda una de estas opciones: dejar de seguir diciendo que se sigue a Foucault o asumir que Foucault es un pensador conservador $^{27}$ que, al poner todo bajo el mismo calibre de su óptica crítica, se desentiende de la relación directa con los conflictos, quedándose en un juego intelectual, moviendo más a la inacción que a la acción, pues su crítica hace sospechar de los que se implican directamente en la crítica de los poderes concretos e invita a pensar, por tanto, en términos de desesperanzada fatalidad (Rorty, 1982; Alonso, 1998), ya que, hágase lo que se haga, el poder sale siempre reforzado ${ }^{28}$. Así, cuando se aborda desde claves directamente políticas, todo queda subsumido en lo que denomina disposiciones fundamentales del saber, como si el único agente fuese EL SABER, cuando se aborda en clave histórico-filosófica, como especialmente ocurre en Las palabras y las cosas (Foucault, 1993).

Interesa aquí especialmente subrayar que, en cualquier caso, Foucault no se queda en lo discursivo ni en ese cambio de régimen de los discursos en que puede conceptuarse una manera de entender la intertextualidad. Lo que este autor se pregunta son las condiciones histórico-sociales que explican que un discurso pueda ser pronunciado o recibido, lo que, a su vez, cabe entender como la propuesta de un esfuerzo de observación tanto de las características de los discursos como de sus condiciones de circulación más inmediatas o más generales, lo que nos parece llevar a las cuestiones del contexto y la representatividad del mismo. Bien es cierto que Foucault se centra más en las técnicas a través de las cuales se ejerce el poder, especialmente discursivas, que en las bases sociales en las que tal poder se apoya.

En las conferencias que conforman La verdad y las formas jurídicas, Foucault (1984) establece el contexto y la historia antes que el análisis de los textos. Aquí, las cosas ocurren realmente, no son eso que denominan los postestructuralistas "un efecto del discurso": "Tenemos asi estos proyectos y textos, $e$ incluso decretos adoptados por las Asambleas. Pero si observamos lo que realmente ocurrió, cómo funcionó la penalidad tiempo después, hacia 1820, en la época de la Restauración en Francia y de la Santa Alianza en Europa, notamos que el siste-

27 Entre los sociólogos, Anthony Giddens (1990) ha sido quien principalmente ha sostenido esta afirmación.

${ }^{28}$ Así, dice: «se produce asi un desplazamiento social que indica claramente cómo la empresa de reforma moral deja de ser una autodefensa penal para convertirse en un refuerzo del poder de la autoridad penal misma» (Foucault, 1984: 105). 
ma de penalidades adoptado por las sociedades industriales en formación, en vías de desarrollo, fue enteramente diferente del que se habia proyectado años antes" (Foucault, 1984: 95). Puede decirse que, a partir de esta cita, Foucault no se queda entre significantes ${ }^{29}$, como parece ocurrir con algunos de sus seguidores. En esta obra, la sociedad de la vigilancia no surge como producto de un discurso. Siguiendo al autor, esta sociedad es una respuesta al crecimiento de las masas proletarias en la ciudad y la asociación de las clases pequeño-burguesas y populares frente a la acción del arbitrario poder judicial (Foucault, 1984: 105).

Es cierto que en no pocas ocasiones, distintas a las señaladas, la concepción foucaultiana del discurso no está clara, añadiendo la confusión entre su discurso y lo que entiende por discurso ${ }^{30}$. Incluso en uno de los textos referidos —La verdad y las formas jurídicas -, la defensa de la materialidad del discurso, como algo material que tiene efectos materiales ${ }^{31}$, y la voluntad de trascender el procedimental análisis de los lingüistas más convencionales, llevan a extender el alcance de lo discursivo y dar al discurso un papel decisivo ${ }^{32}$. Excesivamente decisivo, según nuestro punto de vista, tal como ha sido recogido por los seguidores.

Tal exceso también tiene su fundamento en Foucault. Está cuando reduce el análisis de lo que denomina las producciones discursivas a un análisis de carácter lingüístico, donde el lenguaje parece ser el único hacedor de historia (Foucault, 1994: 828). Está, sobre todo, en esa declaración de antihumanismo con que cierra Las palabras y las $\cos ^{3} \mathrm{~s}^{33}$, anunciando que una episteme que tiene en un lugar fundamental el lenguaje hace desaparecer el hombre. Es aquí

29 La obra está repleta de muestras en las que lo histórico, y no precisamente como texto o disciplina, rebosa lo discursivo: "A finales del siglo XVIII el robo de los barcos, el pillaje de almacenes y las depredaciones en las oficinas se hacen muy comunes en Inglaterra" (Foucault, 1984: 113); "en la historia de las prácticas judiciales me parece que se puede aplicar una hipótesis, proyectar un análisis estratégico del discurso en el interior de procesos históricos reales e importantes» (Foucault, 1984: 154). La misma centralidad de la historia sobre lo discursivo se encuentra en Foucault (1979).

${ }^{30}$ Sobre el discurso de Foucault, véase Casanovas (1987).

${ }^{31}$ La materialidad del concepto de discurso en Foucault aparece tanto en el acento de lo documental, repitiendo que lo que analiza son documentos (Foucault, 1992a), como en la supuesta capacidad de los discursos para materializarse, especialmente para hacerse cuerpo: «Lo que busco es intentar mostrar cómo las relaciones de poder pueden penetrar materialmente en el espesor mismo de los cuerpos sin tener incluso que ser sustituidos por la representación de los sujetos" (Foucault, 1992b). Desde tal perspectiva, la microfísica del poder se opone a una metafísica del poder.

32 «Se trataría de reintroducir la retórica, el orador, la lucha del discurso en el campo del análisis, no para hacer como los lingüistas un análisis sistemático de los procedimientos retóricos sino para estudiar el discurso, aun el discurso de la verdad, como procedimientos retóricos, manera de vencer, de producir acontecimientos, decisiones, batallas, victorias, para retorizar la filosofía» (Foucault, 1984: 158).

33 Se ha interpretado de manera muy distinta el último párrafo de este texto, hasta llegar, como invita Gros (1996: 38), a hacerlo como una retórica propagandística que, sin duda, ayudó al éxito de público de un libro difícil. 
donde el imperio del lenguaje apenas deja intersticios: "El hombre habia sido una figura entre dos modos de ser del lenguaje; o por mejor decir, no se constituyó sino por el tiempo en que el lenguaje, después de haber estado alojado en el interior de la representación y como disuelto en ella, se liberó fragmentándose: el hombre ha compuesto su propia figura en los intersticios de un lenguaje fragmentado" (Foucault, 1993: 374). Sentencia que multiplica las interpretaciones contradictorias: a) el hombre enfrentado al lenguaje; b) el hombre como producto del lenguaje; c) las posibilidades del hombre para la liberación, estando más allá del lenguaje; d) el lenguaje como máquina autónoma que, tras una avería aprovechada por el hombre, vuelve a ponerse en funcionamiento aplastando al hombre, etc.

La ambigüedad ${ }^{34}$ de los textos de Foucault convierte en sospechosa toda interpretación del mismo. Incluso toda voluntad de interpretación de su obra, lo que incluye la ofrecida aquí para criticar a sus seguidores postmodernos. No obstante, señalar que hay otro Foucault distinto al defendido por los postmodernos no es más que un argumento en favor de la existencia de otras formas de analizar los discursos distintas de las propuestas por éstos. Se pueden hacer, al menos, dos preguntas: ¿dónde llega lo discursivo en Foucault? Esto es lo que modesta y sintéticamente se ha hecho para contestar a los postmodernos. La otra: ¿dónde llega lo social en la sociología de Foucault? Algo parcialmente abordado ya por Giddens o Rorty; pero cuya respuesta tal vez abra otra forma - una más - de leer a este autor. Pero esto ya no es objetivo de este trabajo.

${ }^{34}$ Ambigüedad entre distintas obras y en el interior de un mismo título. Ello ha hecho que no falten las controversias donde situar a este autor: ¿crítico revolucionario o neoconservador?, ¿moderno o postmoderno?, como se pregunta Couzens (1994). En la ambigüedad que atraviesa sus escritos, en las imperfecciones que le llevan de una a otra, cifra Foucault la libertad (Foucault, 1992a: 28), cuestión que nos lleva a la obsesión de Foucault por el límite del pensamiento, por el cómo se conforman los límites del pensamiento. Ello le sirve para describir cómo se organiza la represión, lo carcelario, lo que ata. Es una obsesión ética: hay que romper los límites del pensamiento. La ambigüedad expositiva queda así justificada por el carácter fronterizo y paradójico de su obra: mostrar los límites del pensamiento, lo que no puede pensarse, desde el propio pensamiento. Foucault se propone pensar lo que no puede pensarse, lo que le lleva a la historia - puede pensarse ahora lo que no pudo pensarse antes - o a la sospecha sobre todo pensamiento alternativo en el presente, incluido el suyo, ya que, siguiéndose a sí mismo, sólo puede pensarse lo que debe pensarse. Sin por ello intentar justificar a Foucault, hay que reconocer que el giro conservador es más patente en el caso de Niklas Luhmann (por ejemplo, Luhmann, 1992: 97), quien, proyectado en este contexto, vendría a decir algo parecido a que no se puede pensar lo que no se puede pensar. Así, su escritura no sólo ha causado problemas entre sus lectores, generando tanta pasión como desafección; el propio Foucault (1992b: 154) abominó de ella en algún caso concreto, como ocurre con El orden del discurso (Foucault, 1973). 


\section{DECONSTRUCCIÓN: LA PALABRA MÁGICA DEL POSTMODERNISMO}

Si hay un término que abre camino directo al centro de la sensibilidad postmoderna, haciendo saltar todos los tonos mágicos y (anti)míticos que presuponemos cuando manejamos la palabra postmodernidad, ese término es el de deconstrucción, concepto que además viene a hacerse sinónimo, en muchos casos y para muchos autores ${ }^{35}$, de las prácticas de análisis del discurso realizadas después del giro postmoderno. Evidentemente, no vamos a entrar aquí a analizar ni los fundamentos, no fundamentados por definición, del deconstruccionismo ni la obra de los deconstruccionistas ilustres, sea el seductor y encantador - casi de serpientes - Jacques Derrida, tomado justamente como cabeza de fila del movimiento; sean los deconstruccionistas norteamericanos, de la escuela de Yale; como el oscuro y filonazi en su juventud Paul de Man - personaje que abre inmediatamente el abismo heideggeriano y el morbo de la "parte maldita»—, o los elegantes y académicos Geoffrey Hartman, Harold Bloom o J. Hillis Miller ${ }^{36}$. Sólo queremos ver que si seguimos los presupuestos de la deconstrucción nos encontramos con un estilo de análisis de discurso que necesariamente expulsa el mundo de lo social de sus dominios.

Para los deconstruccionistas, ninguna interpretación de un texto puede reclamar una autoridad definitiva, pues el texto mismo porta siempre y de manera constitutiva contradicciones indecibles que socavan su coherencia, que de esta manera siempre se convierte en aparente. La deconstrucción se define así siempre en negativo, levanta "las trampas» de los textos desde un lector contingente que no postula más significado que su propia lectura. Sin referencia ni significado externo, el texto sólo puede apelar a otros textos, en un juego de combinaciones y permutaciones infinitas de significantes que se componen no tanto por ningún principio de identidad con realidad alguna como por «la diferencia». El único sentido de un texto es su diferencia (oposición) a otros textos, el texto es un ente volátil cuya única e inútil aspiración para fijar su significado es, al fin y al cabo, el texto mismo. Todo es deglutido finalmente por «el texto», que se convierte por ello en la realidad única.

El arsenal de la deconstrucción, formado en sus convenciones centrales en

35 Sobre la deconstrucción como movimiento teórico, véanse dos informadísimos libros como son el de Culler (1984) y el de Norris (1998); este último trata de separar -inútilmente, a nuestro modo de ver- deconstrucción de postmodernidad, inutilidad que viene de intentar «filtrar» o «depurar» los conceptos cuando su equivalencia factual viene de los usos sociales, y los efectos políticos, que refuerzan conjuntamente a ambos discursos. Una introducción avanzada y de gran calidad se encuentra en Peñalver (1990).

${ }_{36}$ Es evidente que no podemos aquí citar ni una mínima parte de los trabajos de la escuela deconstruccionista de Yale y la recepción norteamericana de Derrida; como introducción pueden verse dos antologías muy completas e interesantes como son las de Asensi (1990) y Fabb y otros (1989). Sobre el famoso y tortuoso caso de Paul de Man, tan revelador de las confusiones y desorientaciones ideológicas del movimiento, además del clásico de Derrida (1998a), la introducción de Norris (1988). 
el postestructuralismo, con el que de hecho llega a confundirse - si tomamos a este postestructuralismo como el movimiento intelectual que trató de disolver la objetividad y cientificidad de las estructuras y las oposiciones binarias del lenguaje, postuladas explícita o implícitamente por el estructuralismo lingüístico clásico, en un casi inaprehensible juego de saberes, poderes y placeres previos e incluso generadores de lenguaje mismo ${ }^{37}$ - está compuesto de un impresionante conjunto de neologismos y cultismos, cuyo uso, en último término, es la garantía de que el análisis de discurso practicado es una "deconstrucción del texto" realizada en puridad. A este repertorio nos referiremos a continuación por cuanto que -independientemente del valor de sus supuestos filosóficos subyacentes, que pueden ser todo lo apreciables y originales que se quiera, cosa que no vamos a entrar aquí en juzgar - se ha convertido en el conjunto de recetas a seguir por los deconstruccionistas, implicando esto, a nuestro modo de ver, una lejanía cada vez más notoria de los contextos sociohistóricos reales de interpretación y, sin embargo, un ensimismamiento en una retórica bastante cerrada que muchas veces habla de contextos, pero que nunca llega a explicitarlos ni a concebirlos.

Así, el concepto de deconstrucción mismo, tal como lo reclama Derrida, se define siempre en negativo, como hemos dicho. Primero, contra la tradición logocéntrica del pensamiento occidental que confía en la potencia del pensamiento para encontrar significados estables, sin embargo, el conocimiento humano es, según nuestros autores, el producto contingente de prácticas lingüísticas plurisignificativas que se resisten a ser encajadas en cualquier representación de una realidad externa que no sea otra cosa que una narración particular, local y subjetiva. Luego aparece la otra gran tradición engañosa que trata de quebrar el deconstruccionismo: el fonocentrismo, por el cual toda la lingüística moderna había querido encontrar en el habla, en lo oral, la voz natural y auténtica del hombre, considerando a la escritura un lugar secundario, por ser una expresión artificial, forzada y construida fuera de los marcos habituales de la convivencia y, por ello, del sentido auténtico de la existencia del hombre. Sin embargo, para el deconstruccionismo la escritura es la capacidad de crear narraciones mismas, es anterior y fundamento del lenguaje mismo; en el principio no está "la cosa», sino el signo, y el signo no es su referibilidad simple, sino vuelto sobre el propio signo en su infinita capacidad de crear narraciones; por ello, ya no estamos ante una semiología, sino una gramatología que toma los textos como redes sin principio ni final definibles antes por sus huellas y sus vacíos que por su representación ${ }^{38}$.

${ }^{37}$ El paso del estructuralismo al postestructuralismo, con la figura de Roland Barthes como puente generacional y teórico, se estudia en Culler (1978 y 1987). May (1994) hace una revisión de las consecuencias filosóficas y políticas del postestructuralismo, conceptuándolo como un neoanarquismo; por fin, Cuff, Sharrock y Francis (1998: 237 y ss. ) colocan este movimiento ya entre las principales escuelas que forman el mainstream de la teoría sociológica contemporánea.

${ }_{38}$ El núcleo de la exposición de la obra de Derrida lo hacemos a partir de Derrida (1971, 1975, 1989, 1993 y 1997). La deconstrucción derridiana ha seguido por caminos diversos, reali- 
Los deconstruccionistas vuelcan el texto hacia su plano significante - de hecho, para Derrida la historia de la filosofía ha sido la represión del significante, en el más genuino sentido lingüístico, frente al significado tomado logocéntricamente por verdad-, pero ese plano significante no tiene código filológico ni esencia temática única; sólo es una trama de misterios que se refugian entre líneas y que producen efectos contextuales bajo la aparente linealidad y coherencia del texto. Deconstruir no es, pues, ni siquiera interpretar; es buscar las lecturas insólitas y no convencionales que se pueden realizar del texto, seguir todo texto como una incorrección en sí mismo, hacer saltar su lógica, porque toda lógica postulada como esencial y trascendente es en alguna parte ilógica y no puede ser apuntalada nada más que por trampas y trucos que provienen de referencias contingentes e inestables.

Debido a que se rechaza de entrada cualquier determinación del sentido en el texto - por el tema, por su referencia, por sus estructuras lingüísticas subyacentes, etc.-, lo que implica la negación de toda autoridad en la lectura, el deconstruccionismo avanza así en un proyecto de desfundamentación de la hermenéutica, separándolo de la tecnología lingüística o de cualquier pretensión humanística o materialista de encontrar algo exterior al texto que fije su sentido. En el texto no hay referencia — como pretenderían las escuelas realistas - ni actualización de códigos — como postulan los estructuralistas clásicos-; en el texto sólo hay indeterminación y opera por diseminación, toda palabra remite a otra palabra y todo texto remite a otro texto en una cadena infinita de sentidos parcialmente compatibles y, a la vez, parcialmente incompatibles entre sí. Esta diseminación multiplica la complejidad y la inestabilidad de todo texto, haciendo de su significado algo azaroso, ambiguo y forzosamente dependiente de sus contextos de lectura, y dado que estos contextos en Derrida, por ejemplo, vuelven a estar literalmente creados por otros textos y narraciones, el resultado es una lectura realizada con un criterio de relativismo externo y de subjetividad desaforado. Deconstruir es así hallar líneas de diseminación habitualmente indecibles, romper los caminos lógicos del texto para revelar sus silencios, sacar a los discursos de sus ejes para negarlos como textos definitivos.

Y, por fin, aparece otro de los términos fetiches de la deconstrucción, el de diferencia. Creado en la ambigüedad y polisemia del verbo diferir (enfrentarse, separarse, retrasar, posponer, etc.) y el sustantivo diferencia (resto, diversidad, anormalidad, oposición, diferendo, etc.), el concepto de différance de Derrida arrastra y amplifica toda la filosofía de la negación -Nietzsche, Heidegger, etc. ${ }^{39}$ - , para plasmarla en su estrategia de deconstrucción, de cruce y entrecruce de textos para mostrarlos en su infinita repetición y derivas de sentido, en su ausencia

zando (anti)lecturas que van desde el mismísimo fantasma de Marx (Derrida, 1995) a la mitología moderna de la amistad (1998b). Para una visión general de la obra de Derrida, véase Norris (1987).

39 Para avanzar por «las aventuras de la diferencia» hasta llegar a otro tópico asociado a la postmodernidad: el pensamiento débil, ver Vattimo (1986). 
radical de cualquier momento auténticamente original y fundante. Extrapolando y, a la vez, subvirtiendo la idea saussuriana de que el valor del signo siempre viene dado en función de un sistema de diferencias, el deconstruccionismo derridiano invierte el sentido positivo de la lingüística estructural clásica, primero porque deniega que exista algo fuera de la lengua misma que establezca un significado, luego porque utiliza el término diferencia no para marcar una identidad frente a otras sino para negar la esencia de toda identidad.

Apelando a la diferencia se rechaza cualquier intento de totalización del pensamiento — que a estas alturas significa ya directamente la forma más refinada de totalitarismo-, la noción de una identidad esencializada y transparente se rompe y fragmenta en el proceso siempre contingente, cambiante y diferido del lenguaje; todo, absolutamente todo, es definido por su parcialidad, por su particularidad, por su descentramiento. La diferencia, entonces, debe ser entendida como un principio débil de no identidad que hace la significación posible sólo por desplazamiento, por distanciamiento entre significados y significantes; así, tal significación sólo es un efecto indebido y diferido, y el sentido es un nuevo trazo de otros significantes que se han ido combinando y contraponiendo en escrituras y lecturas sucesivas y siempre provisionales y parciales. La diferencia, en suma, es un concepto ambivalente porque se alimenta de la ambivalencia de los propios textos, de su indeterminación, indecibilidad e incitabilidad. Si podemos encontrar alguna huella de significado es porque no hay identidad; la deconstrucción explora y explota la diferencia para encontrar en ella la única y posible, aunque inestable y dudosa, fuente de interpretación.

Las resonancias y connotaciones del término diferencia han sido, quizás, las responsables netas del indudable éxito intelectual y universitario del movimiento deconstruccionista en su conjunto. Además de arrastrar una cadena semántica inquietante y, por ello, fascinante — desaparición, descentramiento, diseminación, discontinuidad, dispersión, desmitificación, desestabilización, etcétera-, presentaba, en su obsesión por fragmentar y fracturar el saber, la posibilidad de pensar desde lo que ha sido considerado minoritario y diferente, desde lo históricamente marginado en el campo del género, de la sexualidad, de la lengua, de la política, de los espacios y territorios. No por casualidad, entonces, los trabajos de Luce Irigaray ${ }^{40}$ para leer los diferentes cierres textuales que han construido la dicotomía hombre-mujer, desde la religión hasta la ciencia, como realidades estables, objetivas totales y su inequívoca llamada a una subjetividad particular y diferente, suelen ser puestos como ejemplo del potencial desfundamentador de la deconstrucción postmoderna tomada en su sentido más amplio. Los efectos de verdad de los textos se forman mediante una red lingüística de exclusiones y diferenciaciones latentes, construidas a partir de

40 Véanse, como ejemplos más representativos, Irigaray (1984 y 1992). Sobre el tema del feminismo, "la diferencia» y la teoría del discurso, véanse las diferentes aportaciones recogidas en Colaizzi (1990). 
una multiplicidad de posiciones discursivas; lenguaje y metalenguaje — todo es metalenguaje por definición- se funden en textos que, tratando engañosamente de prescribir la realidad, sólo son capaces de usar y parasitar otros textos, de acabar cayendo, pues, en el texto infinito como ausencia de realidad objetiva. Si todo es contingente, textual y contextual, todo se puede cuestionar acudiendo a otras contingencias, textos y contextos.

Dejando de lado lo que de radical, de entrada, tenga o pueda tener el proyecto deconstruccionista, aunque hay autores de la talla de Jürgen Habermas que, como se sabe bien, han intentado emparentar a Derrida con una tradición contramoderna y neoconservadora, típica de las lecturas más nihilistas e irracionalistas de Nietzsche ${ }^{41}$. Y teniendo en cuenta, también, que el carácter y la percepción de los usos de la deconstrucción, como la del postmodernismo, en general, varían mucho según países y tradiciones políticas y culturales —en Estados Unidos y Gran Bretaña han sido recibidos siempre asociados a las acciones de los nuevos movimientos sociales y la defensa de las minorías contra el poder de la identidad blanca, positivista, masculina y occidental; en Europa y América Latina la sospecha de su connivencia con el neoliberalismo, el hedonismo individualista y el descompromiso social activo ha hecho negar a muchos de su carácter progresista ${ }^{42}$-, vamos a entrar aquí en las consecuencias que para el análisis e interpretación de los discursos en el campo de la investigación social suponen estas nociones derridianas impregnadas de un anarquismo metodológico extremo y de un relativismo radical e irreductible que en algunos casos bordean peligrosamente el bloqueo solipsista.

Por tanto, reconociendo lo que de antiautoritario y de generador de miradas originales, reveladoras y desveladoras nos ha traído el deconstruccionismo, también tenemos que reconocer las deformaciones, abusos y callejones sin salida en los que nos ha colocado, en muchos casos producto de los excesos de seguidores demasiado entusiastas o incautos, pero también, y eso es necesario decirlo, de los antiprincipios que fundan esta escuela, movimiento, programa, paradigma o como se le quiera llamar. El deconstruccionismo es como el movimiento abstracto en el arte, anula toda referencia figurativa y necesita un relato que nos desentrañe qué son esas impresiones, colores, fragmentos y destellos que hay en la obra para hacerle de algún modo inteligible, para crearlo de nuevo - relato que crea el crítico, el lector, el autor, el deconstructor, todos y ninguno a la vez-. Y hasta ahí todo va o puede ir bien; el problema es decir que la abstracción anula hasta hacer inexistente el modelo, la figura, los suce-

${ }^{41}$ Véanse en esta línea la clásica aportación de Habermas (1989) y la muy crítica visión de todo el movimiento postmodernista hecha por Callinicos (1989), desde un punto de vista abierta y declaradamente marxista. El incombustible historiador del pensamiento crítico Matin Jay (1998) llega a hablar del peligro de un fascismo postmoderno.

${ }_{42}$ Evaluaciones muy diferentes del fenómeno postmoderno nos encontramos en la obra del norteamericano Giroux (1996) o en la del británico Norris (1997), que cuando nos enfrentamos a la visión latinoamericana de Lechner (1988) o a las aportaciones recogidas por Veiga Neto (1997) o por Follari y Lanz (1998). 
sos históricos, otros tipos de arte representacionista y, por lo mismo, las acciones, necesidades y voluntades de los sujetos que han hecho posible la elaboración misma de la obra.

De esta manera, el concepto de texto que maneja la deconstrucción es prácticamente inmanejable en investigaciones concretas. El texto, separado de cualquier anclaje empírico o de referencia social operante, se convierte en una entidad inasible que, además, por la diseminación y el diferimiento de la significación que se postula nos acaba llevando al texto como única antirrealidad absoluta y opresora. Si el discurso, tomado éste como una práctica simbólica que se construye en y construye a los actores sociales en la representación de sus conflictos, intereses y formas de historicidad concretas, nos lleva a las razones prácticas y a los nichos de la vida intersubjetivamente creados, el concepto de texto derivado hasta ese metatexto del que nada puede salir se convierte - a pesar del radicalismo inicial de la propuesta deconstruccionista y de la ironía contra las verdades de la interpretación - en un concepto de tintes autoritarios, no tanto por sus posibles repercusiones políticas — que las puede tenercomo por su incapacidad de dejar cualquier libertad de acción-reacción, interpretación y crítica a los sujetos en sus realidades concretas. Para luego cargar los tintes en una lectura que, por ser infinitamente arriesgada, de hecho no tiene el más mínimo riesgo al poder decir y desdecir todo en un canto a la arbitrariedad absoluta y autocomplaciente ${ }^{43}$.

No es extraño, así, que los supuestos desmontajes y demoliciones deconstruccionistas se realicen en, para y por escritos absolutamente académicos (si no academicistas) y que hayan sido textos literarios, filosóficos y, sobre todo últimamente, científicos los objetos de esta deconstrucción ${ }^{44}$. El análisis del discurso derridiano se convierte así en una teoría, o incluso en una metateoría, una crítica en términos retóricos de los repertorios de los textos y sus efectos de verdad, una lectura «abrasiva» sobre el texto que, por definición, desdeña todo lo demás. Conforme nos vamos alejando de textos y escritos —en el más simple y vulgar sentido de los términos-, conforme los discursos son más cotidianos, más llanos, menos cultos, más inestables e inseguros, por ser también más cálidos, naturales y encarnados en situaciones sociales concretas, el deconstruccionismo se va desentendiendo, quizás porque su provocación va perdiendo interés y fuerza. Los textualistas supuestos del deconstruccionismo

${ }^{43}$ Estos argumentos se desarrollan en McCarthy (1992: 107-137) y en Wolff (1997). Más radical todavía, Mathew Stewart, después de algún intento de traducción jocosa de textos de Derrida - que nos recuerda vagamente a aquellas reescrituras clarificadoras que trataba de hacer C. W. Mills con la obra de Parsons-, acaba con un diagnóstico casi brutal: «En un sentido, la deconstrucción es parasofía elevada a método. Define la filosofía como la actividad parasitaria que consiste en demostrar que cualquier texto, disciplina u otra actividad intelectual que pretenda (o no) representar la totalidad filosófica es inadecuada» (Stewart, 1998: 460).

${ }_{44}$ Como señala Fuchs con respecto al deconstructivismo en sociología de la ciencia: «uno no puede deconstruir la práctica de la ciencia natural simplemente deconstruyendo sus textos. Uno debería entonces deconstruir también laboratorios, máquinas, fundaciones y el estado; una tarea que es claramente excesiva para la critica literaria» (Fuchs, 1992: 19). 
- que acaban convirtiendo toda realidad en un texto- anulan los aspectos de indexicalidad y referibilidad de los discursos hasta dejarlos en sus dimensiones retóricas, sólo una antirretórica se opone a la retórica, sólo una escritura (esta vez en sentido derridiano) a otra. El camino para el elitismo y el oscurantismo retoricista estaba abierto.

En efecto, al disolver los contextos pragmáticos e históricos sociales de los discursos - tanto de los que los enuncian como de los que los interpretanen esa especie de "mundo-texto", todo lo que quedan son los juegos, las ironías y las capacidades para sorprender, molestar o epatar de un lector dispuesto a "textualizar» sus diferencias. De aquí que el único recurso de la crítica final sea alambicar y complicar la lectura, retorcerla hasta hacer sudar al texto (y al otro lector), complejizarla hasta hacerla ininteligible. Romper la simplicidad de la supuesta verdad fragmentando y entrecortando el texto hasta también buscar su fuerza en lo inconsciente y lo intersticial. Pero estos recursos, que bien manejados pueden ser intelectualmente excitantes, cuando se convierten en «recetas textuales» son estériles, gratuitamente oscuros, insoportables en su lectura y perniciosos en sus efectos, al excluir toda razón, toda referencia, toda construcción concreta y toda verosimilitud social ${ }^{45}$.

La altivez y la falta de la menor modestia intelectual que ha mostrado habitualmente el deconstruccionismo le han encerrado en un buen número de mistificaciones y aporías de las que sólo ha podido salir — malamente - acudiendo a su propia retórica (diferencia, diseminación, indecibilidad, etc.); de esta forma, la metacrítica deconstructivista, por mucho que se autoconstruya, no deja de ser una forma de crítica literaria convencional, expuesta en términos clásicos de causalidad, lógica y secuencia, hecha en foros académicos por personas refinadísimas, con estrategias de promoción profesional y comercial, con usos idiomáticos producto de centenares de horas de educación, mostrando erudición poderosa y, en suma, beneficiarias de todos los productos del «logos» occidental y de la división del trabajo que ha posibilitado ese logos. Del mismo modo, el deconstructivismo sólo puede envolver en palabrería todo aquello

45 Eagleton (1993 y 1996) lleva este razonamiento hasta sus últimas consecuencias, haciendo una verdadera crítica política del estilo del deconstruccionismo y el postmodernismo. De esta manera, en la última obra referenciada de este autor, justamente en el capítulo que se dedica a «las falacias» del postmodernismo, se considera a éste como algo que se sitúa mucho más allá de un error teórico, se define como una ideología en toda regla y en el sentido más fuerte del concepto, que hace una apología del particularismo complaciente y que elimina la capacidad de acción de los actores para disolverlos en los signos y simulacros del mercado cultural. En esta misma línea, Xavier Gobás (1998: 112) argumenta: "Puesto que para la estrategia reflexiva postmoderna no resulta posible separar la ficción de otras clases de discurso, como el histórico o el documental, el individuo es percibido en su incapacidad para discernir, en uso de su razón, la ficción o la falsedad de la realidad y la verdad. Estas cosideraciones configuran la muerte del argumento demostrativo sobre los acontecimientos o hechos, y la muerte, por lo tanto, del sujeto.» El desprecio por la argumentación del pensamiento postmoderno nos conduce, también, al peligro inminente de la trivialización de la violencia, porque "si todo da igual" no hay forma de establecer criterio para escuchar, responder e intercambiar, lo que nos pone al lado del abismo; ver Pereda (1998: 327-339). 
que está "fuera del texto", como son todos los problemas que se derivan de la "gramática de los motivos y las motivaciones», sean físicas, biológicas, sociales, psicológicas o cualquier otro que se quiera. El muy difundido «caso Sokal», en el que este físico norteamericano — parodiando y llevando a los extremos más enloquecidos el estilo derridiano, pero trucando, descaradamente, en muchos casos, las más elementales, conocidas y viejas ecuaciones físicas- entrase por la puerta grande de la deconstrucción para luego descubrir amargamente su parodia, es buen ejemplo de que el textualismo deconstructivista se encierra en la mayoría de las ocasiones en un mundo autista y, en el fondo, autocomplaciente que se autojustifica en su propio, e ignoto, discurso ${ }^{46}$.

Porque el problema de la dificultad del estilo deconstruccionista va mucho más allá de su falta de claridad o de su reclamo de un esfuerzo desmedido para ser leído - si por esto fuera, gran parte de la historia del pensamiento occidental debería de ser proscrita-; es un problema de estilo de acercamiento a los problemas de la interpretación. Esta forma, a la vez infatuada y críptica de hacer, sólo es posible cuando a los textos — los leídos y los escritos - se les da un valor final y último, cuando no se reconocen los límites y los destinos sociales de los textos, cuando, en suma, el texto es algo a destruir para sustituir por otro texto (a ser posible, el mío). El texto es así máximamente negado y por eso, a la vez, máximamente afirmado, y con ello es negado cualquier sujeto y, en lo que aquí nos interesa, el sujeto social. Para ser encumbrada, por el contrario, la figura narcisista del lector/escritor/deconstructor.

Sin embargo, y sin entrar aquí en el eterno problema de la validez y corrección de la interpretación, sí que indicaremos que frente a la tendencia derridiana a violentar el texto - y, en suma, sólo valorar sus silencios- hay otras hermenéuticas que prefieren escuchar la voz de los actores individuales y colectivos de los discursos. Por esto, frente a la dispersión y diseminación de cualquier sentido, prefieren encontrar los sentidos de los discursos en situaciones sociohistóricas multideterminadas. Y frente a la negación de toda verdad, prefieren explorar las representaciones concretas y socialmente construidas de la verdad que han empujado a los sujetos a interaccionar, actuar y hablar. En suma, hermenéuticas que prefieren no negar de antemano la conciencia, consistencia y significado de los textos, sino rastrear en ellos la pragmática de los discursos, haciendo concordar el «horizonte» de los posibles significados de los textos con

${ }^{46}$ No vamos, lógicamente, a entrar aquí en el tema de Alan Sokal y su artículo paródico, ni tampoco a referenciar la enorme repercusión bibliográfica que ha tenido el tema — repercusión que ha ido desde las revistas científicas hasta los suplementos culturales de los diarios, pasando por las páginas electrónicas de la w.w.w.-_; nos conformaremos con enviar al lector, para que juzgue por sí mismo, a los dos artículos, el paródico y la rectificación del propio Sokal —ya en castellano (Sokal, 1998a y 1998b)—, y al interesante libro de Sokal y Bricmont (1997), así como también mostrar la preocupación de que la crítica contra el confusionismo postmoderno se convierta en el retorno de la más dura y convencional caza de brujas positivista y tecnocrática, o en un nuevo blindaje a la crítica social de los científicos duros, algo que con este "caso" también ha empezado a producirse. 
«horizontes» de la conciencia individual y colectiva, así como de la experiencia histórico-cultural del lector ${ }^{47}$.

Por tanto, evidentemente, los discursos no tienen un significado único, pero no por ello tampoco tienen ningún significado, o cualquier significado que el lector les quiera dar. Por ello hay que empezar por interpretar el significado que el autor pretende para sus propios enunciados, siguiendo por el producto textual mismo como realidad positiva con cierta autonomía y con efectos pragmáticos que van más allá de sus "huecos» o "desdecires», entrando, también, en la representación y construcción de realidades, y, por fin, encontrando las condiciones sociohistóricas de recepción y reproducción de los textos y discursos. En suma, si al demoler la supermetafísica noción de significado trascendental nos llevamos por delante cualquier significado, por intersubjetivo, pragmático, dialógico, contextual y concreto que éste sea, el resultado es acabar con la posibilidad no sólo de interpretar, sino de que exista realidad social que construye a - y es construida por- actores históricos.

Para no caer en el descriptivismo, el realismo o el empirismo más ingenuo, por la vía positivista, o en metafísica clásica, por la vía idealista, no podemos subsumirlo todo en una «razón textual» absoluta que en el fondo es la sinrazón práctica. Sin «razón social», la deconstrucción y su «lectura interesada de la tradición» no es más que un juego de textos y palabras remitiendo al eco de otros textos y palabras, pero si las palabras tienen sentido con relación a otras palabras es porque se troquelan en patrones sociales y en escenarios institucionales. Los discursos no son sólo palabras, son formas de práctica social que nos remiten a luchas y jerarquías políticas, a contextos pragmáticos, a nichos institucionales, a condiciones materiales y a prácticas no discursivas en un sentido estricto. Los discursos - y su interpretación - nos remiten, pues, a «razones prácticas», en el sentido que le da a este concepto Pierre Bourdieu, es decir, al conjunto de relaciones entre las posiciones y las tomas de posición ${ }^{48}$. En consecuencia, en sociedad, existen limites de posibilidad de los discursos y limites de sus inter-

${ }^{47}$ Es evidente que estas páginas están inspiradas en varias críticas bien conocidas a la deconstrucción, y específicamente en las de Gadamer (1998: 57-117) y las de Steiner (1998: 145-166); merece la pena, también, revisar los diferentes trabajos que compila Eco (1995) sobre el tema de la interpretación y la sobreinterpretación. La polémica entre filosofía hermenéutica gadameriana y deconstrucción se encuentra muy bien presentada en López Sáenz (1997: 57-82) y Grondin (1999).

${ }^{48}$ Véase Bourdieu (1997a y 1997b), y una aplicación a la política concreta actual en Bourdieu (1998). En otra de sus obras, Bourdieu argumenta convincentemente sobre el carácter no tanto racional (tomando el concepto en su sentido utilitarista, calculador y abstracto) como razonable, de la conducta de los agentes sociales, esto es, si los actores se comportan en un ajuste permanente a los espacios sociales de oportunidad conflictivamente construidos; de esta manera, su remozado, célebre y muy utilizado concepto de habitus serviría como mediador entre los sujetos y sus razones objetivas (Bourdieu y Wacquant, 1994: 107-108). Contra esta última aportación y, en general, contra el logocentrismo y el totalitarismo encubierto que encubriría el "proyecto Bourdieu" se pronuncia el libro de Verdès-Leroux (1998: 200-201), en el que parece el último intento, por el momento, de atacar la obra de Bourdieu como si fuera una especie de fortaleza sitiada; para lo que ya empieza conocerse como el caso Verdès-Leroux, ver Martel (1998). 
pretaciones — límites históricos, políticos, económicos, situacionales, etc.—, de manera que la mayor o menor plausibilidad de los discursos y sus interpretaciones vienen del mayor y mejor reconocimiento contextual de esos límites, aunque sea para superarlos o subvertirlos.

En resumen -y para finalizar este punto-, el deconstruccionismo ha abierto caminos insolentes y efectivos (efectistas) en la crítica de los "pasos en el vacío" de los textos académicos, pero marchando deslumbrado en pos de demoler todas las falsas dicotomías fundantes del gran texto que forma el pensamiento occidental en su conjunto, se ha olvidado de demasiadas cosas modestas y elementales que le dan a la interpretación de los textos y discursos el carácter de práctica social concreta, con usos concretos, realizada por actores con fines pragmáticos y con estrategias construidas en el seno de una comunidad institucionalmente asentada que impone motivos extratextuales al significado del texto. Como señala Stuart Hall, refiriéndose al conjunto del postestructuralismo, éste sitúa la teoría del discurso — por su énfasis en la pérdida de todo significado - en un punto donde es imposible analizar la desigualdad de una formación social concreta, o incluso apreciar la "unidad en la diferencia» que toda estructura social compleja presenta en su producción y reproducción permanente (Hall, 1998: 29).

\section{MÍNIMO BALANCE}

Si hay algo en común que tienen las tres corrientes de análisis postmoderno de los discursos es la pérdida de relación con el significado, con la referencia. El discurso se convierte en un juego de significantes. Significantes cuyo engarce - gramática - se convierte en objeto de sospecha al imponer un orden, en los deconstructivistas. Significantes que se cruzan, de un discurso a otro, en los intertextualistas. Significantes-documentos que ya no se analizan desde la representación, como verdad de algo exterior al documento, sino en su relación con una masa de significantes-documentos, en los más fieles foucaltianos. Significantes que son sólo armas en la lucha situacional entre los interlocutores, en los constructivistas. Si unos «textualizan» todo, otros "conversacionalizan" todo. Como dice Lucy (1997: 57), se pasa, sin solución de continuidad, de la codificación del lenguaje a la codificación de las situaciones en juegos del lenguaje. El sociólogo empírico se ve entonces en la necesidad de buscar el significado por otros caminos, pues se le suelen demandar argumentos para operar después sobre tales significados.

Si en la trayectoria autónoma que toman los discursos en deconstructivistas e intertextualistas no hay lugar para los sujetos, convirtiendo a la gente en meros receptores acríticos de discursos del poder, en los constructivistas sólo parece haber individuos sin condicionamientos sociales. Es decir, el análisis postmoderno de los discursos se mueve entre la ausencia de agencia o la agencia vacía, entre la omnipotente estructura y la ausencia de estructura. Lo pri- 
mero condena el análisis a la aplicación de un rígido modelo analítico - casi siempre destinado a subrayar las maquiavélicas posibilidades del poder- a toda situación. Lo segundo condena el análisis a una sucesión de anécdotas particulares situacionistas, donde cualquier interpretación parece válida. Entre la única interpretación y las interpretaciones infinitas, tal vez pueda caber la interpretación que busca el sentido a lo que la gente dice, hace y puede llegar a hacer. La interpretación de sujetos concretos.

Es fundamental, por tanto, limitar cualquier pretensión a sobreinterpretar la autonomía de los códigos, textos y discursos, lo mismo que es fundamental rechazar la pretensión "materialista vulgar» de reducirlos a meros derivados milimétricos de la estructura social. El lenguaje y las representaciones simbólicas tienen un papel fundamental en la construcción de los procesos y las prácticas sociales, pero estas prácticas tienen dimensiones fácticas y extradiscursivas que no se pueden reducir a su dimensión textual si no es cayendo en un pansemiologismo estéril e idealista. La hipostatización del discurso es tan aberrante en cuanto a sus resultados intelectuales como la de la pretensión del sujeto esencial, la del significante trascendental, o la del conocimiento como espejo de la realidad, temas todos ellos contra los que se han realizado las aportaciones postmodernas. Una interpretación mínimamente plausible y consistente de los discursos tiene forzosamente que localizar la producción y reproducción de estos textos y discursos en las acciones de sujetos históricos que se sitúan dentro de marcos materiales y sociales con una entidad y una potencia que no pueden ser en ningún caso derivadas de su textualización. La huida del mecanicismo materialista -o de su reverso simétrico, el idealismo humanistasólo se resuelve apelando a la complejidad y a la multideterminación de dimensiones de lo social, operando en situaciones pragmáticas e históricas y no confundiéndolo todo en un texto, intertexto o metatexto del que se puede inferir lo que se quiera según la arbitrariedad del lector.

Es evidente que los hechos y las estructuras sociales se hallan siempre mediatizados por y producidos en ámbitos discursivos, pero no podemos decir - como han pretendido implícita y explícitamente las teorías de sensibilidad postmoderna- que los hechos sociales sean sólo articulaciones discursivas. Comprender la interacción entre textos, estructuras sociales y significados de la acción es una cosa muy diferente a pretender el fin de la historia, los sujetos, las metanarraciones - o el fin de todo para acabar antes- y su diseminación en una pluralidad de textos.

El revulsivo que ha supuesto el postmodernismo para criticar el sujeto esencial o trascendente - o cualquier forma de sujeto cartesiano filosófico, psicológico o económico — ha terminado en la fuga nihilista de acabar con todo sujeto. Aquí nos parece una vía más sensata e intelectualmente productiva observar a sujetos empíricos construyéndose mediante prácticas discursivas, con motivos concretos y en nichos históricos e institucionales operantes. Los textos no son elementos todopoderosos sino cristalizaciones de discursos, que tienen que interpretarse en relación con las condiciones y usos prácticos que 
intervienen en su generación, formalización y recepción. Los actores individuales y sociales son también agentes — conflictivos- de la discursividad y no sólo meros efectos degradados de ésta.

Cuando aparecen los sujetos, aparecen en sistemas institucionales que no se pueden reducir a "textos cristalizados", sino que tienen que ser tomados por formas activas de reproducción del poder y de mediación y resolución de los conflictos. El postmodernismo, al perder de vista las condiciones concretas en las que se producen e interpretan los discursos, cae o bien en una especie de adoración de un poder tan abstracto que es irreconocible o en una forma de pluralismo apocalíptico y negativista — no demasiado diferente del pluralismo liberal aunque teñido de matices libertarios- en la que todos los textos se anulan, entrecruzan y deconstruyen sin que ninguno sea capaz de tener la más mínima capacidad de reflejar realidad alguna. De esta forma aparecen intereses, jerarquías y poderes sociales concretos y formas conflictivas en los dominios de la significación -como la ideología y su capacidad para formar hegemonías políticas y culturales-, que el postmodernismo deja pasar para crear una enorme ceremonia de la confusión.

Otro aspecto paralelo y que determina también el estilo de investigación que podemos esperar de la mentalidad postmoderna es su pose - en última instancia más retórica que otra cosa- de escepticismo cínico y sarcástico ${ }^{49}$. Este sarcasmo que no es nada más que llevar la ironía — sentimiento postmoderno por excelencia - hasta sus últimas consecuencias, fundiendo un relativismo extremo - que acaba en una desfundamentación también de cualquier ética que no sea puramente adaptativa, contingente y fragmentaria- con un jugueteo estético que contra todo canon defiende el pastiche, la fusión de estilos y la supresión de barreras entre lo considerado como cultura y moda. Esta investigación "sin valores» acaba impidiendo el conocimiento social crítico, para festejar con una sonrisa sardónica el triunfo de los poderes más convencionales, y fundamentalmente el poder del mercado, donde los autores postmodernos se desenvuelven con facilidad y donde no rechazan competir. El relativismo que ha introducido el postmodernismo puede ser vivificador y quitar muchas telas de araña que cuelgan de los saberes contemporáneos, pero este relativismo tiene que ser fundamentado en los procesos de creación intersubjetiva, pragmática y consensual de los valores, no en una declaración unilateral de que no hay ninguna realidad normativa posible. Sólo existe conocimiento social como proceso dialógico y reflexivo, producto del enfrentamiento entre visiones que portan pretensiones de validez sobre el mundo y que buscan, de hecho, su transformación práctica, sea de manera directa o indirecta.

49 Entre las corrientes postmodernas de análisis del discurso aquí revisadas cabe excluir de este tono a las posiciones intertextualistas, precisamente porque parten de una posición expresa socialmente más crítica y comprometida más allá de los textos; el problema es que muchos de estos análisis, a pesar de sus buenas intenciones de partida, al sacralizar la dimensión textual hasta prácticamente hacer desaparecer cualquier otra, limitan los efectos críticos de sus postulados iniciales. 
En suma, el análisis postmodernista del discurso poco aporta a las herramientas de las que parte para destruir (la fenomenología, la hermenéutica, el análisis estructural, la teoría crítica, la lectura de la intertextualidad inequívocamente sociolingüística de Bajtin, etc.) en lo que se refiere a los elementos prácticos de conocimiento de lo social. Sus exageraciones y ampulosidades han podido despertar conciencias y abrir interpretaciones agresivamente originales, frente a los estudios «tecnológicos» o positivistas, pero también han arrastrado y han abierto paso a una serie de valores y posturas estéticas y retóricas (nihilismo, individualismo, relativismo extremo, confusionismo, sarcasmo, etc.) que ocultan, más que desvelan, los procesos de construcción simbólica de lo social. Para la investigación social parece más lógica una razón práctica basada en el reconocimiento de los sujetos concretos que una razón textual que proclame la disolución de todos ellos. Como dice Brian McHale, al referirse al término postmodernista: «nada relacionado con este término carece de problemas, nada de lo que le concierne es enteramente satisfactorio» (McHale, 1987: 3). Despues de la postmodernidad, confiemos, pues, en otra modernidad (Lash, 1999), en la modernidad reflexiva del futuro.

\section{REFERENCIAS BIBLIOGRÁFICAS}

ALONSO, L. E. (1998): La mirada cualitativa en sociología, Madrid: Fundamentos.

ANDERSON, P. (1998): The Origins of Postmodernity, Londres: Verso.

AsEnsi, M. (ed.) (1990): Teoría literaria y deconstrucción, Madrid: Arco.

AugÉ, M. (1995): Hacia una antropología de los mundos contemporáneos, Barcelona: Gedisa.

BAjTIN, M. (1989): Teoría y estética de la novela, Madrid: Taurus.

BAUdRILlard, J. (1996): El crimen perfecto, Barcelona: Anagrama.

Bauman, Z. (1993): Postmodern Ethics, Oxford: Blackwell.

Bell, D. (1997): «El fin del modernismo», en Claves, núm. 78, diciembre.

Berman, M. (1988): Todo lo sólido se desvanece en el aire, Madrid: Siglo XXI.

Berger, A. A. (ed.) (1998): The Postmodern Presence, Londres: AltaMira Press.

Bonnel, V. E., y Hunnt, L. (1999): «Introducción», en V. E. Bonnel y L. Hunnt (eds.), Beyond the Cultural Turn. New Directions in the Study of Society and Culture, Berkeley: University of California Press.

BourdieU, P. (1997a): Capital cultural, escuela y espacio social, México: Siglo XXI.

- (1997b): Razones prácticas. Sobre la teoría de la acción, Barcelona: Anagrama.

- (1998): Contre-feux, París: Liber/Raisons d'Agir.

Bourdieu, P., y Wacquant, L. J. D. (1994): Per a una sociologia reflexiva, Barcelona: Herder.

Bravo, P., y Paoletti, M. (1999): Borges Verbal, Barcelona: Emecé.

CASANOVAS, P. (1987): "Notas sobre pragmática y metapragmática en el lenguaje literario de Michel Foucault", en R. Máiz (comp.), Discurso, poder, sujeto. Lecturas sobre Michel Foucault, Santiago de Compostela: Univ. Santiago de Compostela.

Callinicos, A. (1989): Against Postmodernism: A Marxist Critique, Cambridge: Polity Press.

Clifford, J. (1995): Dilemas de la cultura, Barcelona: Gedisa.

ColaizzI, G. (ed.): Feminismo y teoría del discurso, Madrid: Cátedra.

Collier, G.; Minton, H., y Reynolds, G. (1996): Escenarios y tendencias de la Psicología Social, Madrid: Tecnos.

Connor, S. (1996): Postmodernist Culture, Oxford: Blackwell. 
Couzens Hoy, D. (1994): «Foucault: Modern or Postmodern?», en B. SMART, Critical assessments, Londres: Routledge, pp. 281-301.

Cuff, E. C.; Sharrock, W. W., y Francis, D. W. (1998): Perspectives in Sociology, Londres: Routledge.

Culler, J. (1978): La poética estructuralista, Barcelona: Anagrama.

- (1984): Sobre la deconstrucción. Teoría y crítica después del estructuralismo, Madrid: Cátedra.

- (1987): Barthes, México: Fondo de Cultura Económica.

- (1998): «Presupposition and Intertextuality», en V. E. Taylor y Ch. E. Winquist (eds.), Postmodernism. Critical Concepts, vol. 11, Londres y Nueva York: Routledge, pp. 20-33.

Denzin, N. K., y Lincoln, Y. (eds.): Handbook of Qualitative Research, Thousand Oaks, California: Sage.

DerridA, J. (1971): De la gramatología, Buenos Aires: Siglo XXI.

- (1975): La diseminación, Madrid: Fundamentos.

- (1989): Escritura y diferencia, Barcelona: Anthropos.

- (1993): La deconstrucción en las fronteras de la filosofía, Barcelona: Paidós.

- (1995): Espectros de Marx, Madrid: Trotta.

- (1997): El tiempo de una tesis. Deconstrucción e implicaciones conceptuales, Barcelona: Proyecto A.

- (1998a): Memorias para Paul de Man, Barcelona: Gedisa, 2. a ed.

- (1998b): Politicas de la amistad, Madrid: Trotta.

DiJK, T. A. (1985): Handbook of Discourse Analysis, Londres: Academic Press (4 vols.).

Eagleton, T. (1993): Una introducción a la teoría literaria, Madrid: Fondo de Cultura Económica.

- (1996): The Illusions of Postmodernism, Oxford: Blackwell.

ECO, U. (1988): Apostillas a "El nombre de la rosa», Barcelona: Lumen (reimp.).

- (1998): Cinco escritos morales, Barcelona: Lumen.

ECO, U., y otros (1995): Interpretación y sobreinterpretación, Cambridge: Cambridge University Press.

FABB, N., y otros (eds.) (1989): La lingüistica de la escritura, Madrid: Visor.

FAIRCLOUGH, N. (1989): Language and power, Londres y Nueva York: Longman.

- (1992): Discourse and social change, Cambridge: Polity Press.

- (1995): Media discourse, Londres: Edward Arnold.

- (1997): "Critical discourse analysis in the 1990": challenges and responses», en E. RiBeIro Pedro, Discourse analysis. Proceeding of the 1st International Conference on Discourse Analysis, Lisboa: Colibri.

FOLLARI, R., y LANZ, R. (eds.) (1998): Enfoques sobre posmodernidad en America Latina, Caracas: Sentido.

Foucault, M. (1973): El orden del discurso, Barcelona: Tusquets.

- (1979): Historia de la locura en la época clásica, Madrid: Fondo de Cultura Económica (reimp.).

- (1984): La verdad y las formas jurídicas, México: Gedisa.

- (1992a): L'archéologie du savoir, París: Gallimard (reimp.).

- (1992b): Microfísica del poder, Madrid: La Piqueta.

- (1993): Las palabras y las cosas, México: Siglo XXI (reimp.).

- (1994): Dits et écrits, París: Gallimard.

FuCHS, S. (1992): "Relativism and Reflexivity in the Sociology of Scientific Knowledge», en G. Ritzer (ed.), Metatheorizing, Newbury Park (Cal.): Sage.

Gadamer, H. G. (1998): El giro hermenéutico, Madrid: Cátedra.

Gabilondo, A. (1990): El discurso en acción. Foucault y una antología del presente, Barcelona: Anthropos.

Gellner, E. (1994): Posmodernismo, razón y religión, Barcelona: Paidós.

GIDDENS, A. (1990). «El estructuralismo, el postestructuralismo y la producción de la cultura», en A. Giddens y J. Turner (comps.), La teoría social hoy, Madrid: Alianza. 
Giroux, H. A. (1996): Placeres inquietantes. Aprendiendo la cultura popular, Barcelona: Paidós. GODÁs, X. (1998): Postmodernismo: La imagen radical de la desactivación política, Barcelona: El Roure.

Grondin, J. (1999): Introducción a la hermenéutica filosófica, Barcelona: Herder.

Gros, F. (1996): Michel Foucault, París: PUF.

Habermas, J. (1989): El discurso filosófico de la modernidad, Madrid: Taurus.

- (1994): Ensayos políticos, Barcelona: Península (2. ${ }^{\mathrm{a}}$ ed.).

HALL. S. (1998): «Significado, representación e ideología: Althusser y los debates postestructuralistas», en J. Curran, D. Morley y V. Walkerdine (eds.), Estudios culturales y comunicación, Barcelona: Paidós.

Harvey, D. (1989): The Condition of Postmodernity, Oxford: Blackwell.

HowarTh, D. (1997): "Teoría del discurso», en D. Marsh y G. Stoker (eds.), Teoría y métodos de la ciencia politica, Madrid: Alianza.

ÍNIgUeZ, L. (1997): «Discourses, Structures and Analysis: What Practices? In Which Contexts?», en T. Ibáñez e L. Íñiguez (eds.), Critical Social Psychology, Londres: Sage.

IRIgARAY, L. (1984): Éthique de la différence sexuelle, París: Minuit.

- (1992): Yo, tú, nosotras, Madrid: Cátedra.

JAMESON, F. (1996): Teoría de la postmodernidad, Madrid: Trotta.

JAY, M. (1998): Cultural Semantics. Key Words of Our Time, Amherst (Mass.): Universty of Massachusetts Press.

JENCKS, Ch. (1977): El lenguaje de la arquitectura postmoderna, Barcelona: Gustavo Gili.

Kellner, D. (1990): "The Postmodern Turn: Positions, Problems, and Prospects», en G. Ritzer (ed.), Frontiers of social theory. The new syntheses, Nueva York: Columbia Univ. Press.

LASH, S. (1997): Sociología del postmodernismo, Buenos Aires: Amorrortu.

- (1999): Another Modernity. A Different Rationality, Oxford: Blackwell.

LASH, S., y URRY, J. (1996): Economies of Signs and Space, Londres: Sage.

LeCerCle, J. J. (1990): «Postmodernism and Language», en R. Boyne (ed.), Postmodernism and Society, Londres: McMillan.

Lechner, N. (1988): «Un desencanto llamado postmodernidad», Punto de Vista/Buenos Aires, 33, septiembre-diciembre, pp. 21-39.

Lemert, Ch. (1999): Postmodernism Is Not What You Think, Oxford: Blackwell (2. $\left.{ }^{\mathrm{a}} \mathrm{ed}.\right)$.

LÓPEZ SÁENZ, M. C. (1997): «Fiolosofía hermenéutica y deconstrucción», en Revista de Filosofía, vol. X., núm. 18.

Luhmann, N. (1992): Sociología del riesgo, México: Universidad Iberoamericana/Universidad de Guadalajara.

LuCY, N. (1997): Postmodern Literary Theory, Londres: Blackwell.

LYON, D. (1996): Postmodernidad, Madrid: Alianza.

LYOTARD, J. F. (1984): La condición postmoderna, Madrid: Cátedra.

Marietti, A. K. (1985): Michel Foucault. Archéologie et généaologie, París: Libraire Générale Française.

MARTEL, F. (1998): "Jeannine Verdès-Leroux: contre Bourdieu», Magazine Littéraire, 369, octubre.

Martín Rojo, L., y Callejo, J. (1995a): «Sexismo de cuello blanco», Ábaco, 6-7.

- (1995b): "Argumentation and inhibition: Sexism in the discourse of Spanish executives», Pragmatics, vol. 5, núm. 4, diciembre.

May, T. (1994): The Political Philosophy of Poststructuralist Anarchism, Pennsylvania: Pennsylvania State University Press.

MCCARTHY, Th. (1987): La teoría crítica de Jürgen Habermas, Madrid: Tecnos.

- (1992): Ideales e ilusiones. Reconstrucción y deconstrucción en la teoría crítica contemporánea, Madrid: Tecnos.

McHale, B. (1987): Postmodernist Fictions, Londres y Nueva York: Routledge.

MitrA, A. (1999): "Characteristics of the WWW Text: Tracing Discursive Strategies», JCMC, Journal of Computer-Mediated Communication, 5 (1), septiembre, revista electrónica (http://www.ascusc.org/jcmc/vol5/issue1/mitra). 
Nicholson, L., y Seidman, S. (eds.) (1995): Social Postmodernism. Beyond identity politics, Cambridge: Cambridge University Press.

NORRIS, Ch. (1987): Derrida, Londres: Fontana.

- (1988): Paul de Man: Deconstruction and the Critique of Aesthetic Theory, Londres: Routledge.

- (1997): Teoría acrítica. Postmodernismo, intelectuales y Guerra del Golfo, Madrid: Cátedra.

- (1998): ¿Qué le ocurre a la postmodernidad?, Madrid: Tecnos.

PAZ, O. (1974): Teatro de signos, Madrid: Fundamentos.

Peñalver, P. (1990): Deconstrucción, Barcelona: Montesinos.

Pereda, C. (1998): «Argumentación y violencia», en A. Sánchez Vázquez (ed.), El mundo de la violencia, México: UNAM/Fondo de Cultura Económica.

PotTer, J. (1996): Representing reality. Discourse, Rhetoric and Social Construction, Londres: Sage.

— (1997): «Discourse and Critical Social Psychology», en T. Ibáñez y L. Íñiguez (eds.), Critical Social Psichology, Londres: Sage.

RÁBAGO, J. (1995): «El doble juego de la postmodernidad en la arquitectura», en H. Orozco (comp.), Postmodernidad en el mundo contemporáneo, México: Instituto Tecnológico y de Estudios Superiores de Oriente.

ReYNOSO, C. (1991): «Presentación», en C. Reynoso (comp.), El surgimiento de la antropología posmoderna, México: Gedisa.

Rio, A. del (1996): Historia de la literatura española, Barcelona: Ediciones B, vol. 2. ${ }^{\circ}$.

Ripalda, J. M. (1996): De Angelis. Filosofia, mercado y postmodernidad, Madrid: Trotta.

RORTY, R. (1982): Consequences of Pragmatism. Essays 1972-80, Minneapolis: Univ. Minnesota Press.

SMART, B. (1992): Postmodernity, Londres: Routledge.

SOKAL, A. (1998a): «Transgrediendo los límites: hacia una hermenéutica transformadora de la gravedad cuántica», La Balsa de la Medusa, núms. 45-46.

- (1998b): «Epílogo (remitido a Social Text)», La Balsa de la Medusa, núms. 45-46.

SOKAL, A., y BRICMONT, J. (1997): Impostures Intellectuelles, París: Odile Jacob.

SteIneR, G. (1998): Presencias reales, Barcelona: Destino.

STEWART, M. (1998): La verdad sobre todo. Una historia irreverente de la filosofia con ilustraciones, Madrid: Taurus.

Vattimo, G. (1986): Las aventuras de la diferencia. Pensar después de Nietzsche y Heidegger, Barcelona: Península.

VÁzQUez García, F. (1995): Foucault. La historia como crítica de la razón, Barcelona: Montesinos.

Veiga Neto, A. J. (ed.) (1997): Crítica postestructuralista y educación, Barcelona: Laertes.

Verdès-LerouX, J. (1998): Le savant et la politique. Essai sur le terrorisme sociologique de Pierre Bourdieu, París: Grasset.

WATERS, M. (1994): Modern Soiological Theory, Londres: Sage.

WOLFF, J. (1997): La producción social del arte, Madrid: Istmo.

YURKIEVICH, S. (1996): La movediza modernidad, Madrid: Taurus. 


\begin{abstract}
This paper sets out to provide a critical analysis of different poststructuralist-discourse schools in terms of their contribution to the shaping of the cultural phenomenon which goes by the name of postmodernity. By examining various fields of work in the field of postmodernity discourse-analysis — and which have been summed up in three tendencies: intertextualist, constructivist and deconstruccionist - the authors attempt to appraise their real potential for contributing to social knowledge, also highlighting the danger of confounding practices of text - and discourse-analysis and interpretation with an alleged postmodern phase of social research. The authors come out in favour of a sociological analysis of these discourses as a form of critical reconstruction, basically linked with the status and historical contextualisation of the enunciation; interpretation based, therefore, on the social force and on the specific communicative spaces which articulate and frame the discourses of the specific actors as significant practices.
\end{abstract}

